(C) 2008 American Geophysical Union

An edited version of this paper was published by $\underline{A G U}$.

\title{
Transport and variability of the Antarctic Circumpolar Current south of Africa
}

\author{
Sebastiaan Swart ${ }^{1,{ }^{*},}$ Sabrina Speich², Isabelle J. Ansorge ${ }^{1}$, Gustavo J. Goni ${ }^{3}$, Sergey Gladyshev ${ }^{4}$, \\ Johann R. E. Lutjeharms ${ }^{1}$
}

\footnotetext{
${ }^{1}$ Department of Oceanography, University of Cape Town, Rondebosch, 7701, South Africa.

${ }^{2}$ Laboratoire de Physique des Oceans, IFREMER, Universite de Bretange Occidentale, Brest, France.

${ }^{3}$ Atlantic Oceanographic and Marine Laboratory, Physical Oceanography Division, NOAA, Miami, Florida, USA.

${ }^{4}$ Shirshov Institute of Oceanology of the Russian Academy of Sciences, 36 Nakhimovskii Prospect, Moscow, 117997, Russia.

*: Corresponding author : Swart S., email address : sebastiaan.swart@uct.ac.za
}

\begin{abstract}
:
Data from five CTD and 18 XBT sections are used to estimate the baroclinic transport (referenced to 2500 dbar) of the ACC south of Africa. Surface dynamic height is derived from XBT data by establishing an empirical relationship between vertically integrated temperature and surface dynamic height calculated from CTD data. This temperature-derived dynamic height data compare closely with dynamic heights calculated from CTD data (average RMS difference $=0.05 \mathrm{dyn} \mathrm{m}$ ). A second empirical relationship between surface dynamic height and cumulative baroclinic transport is defined, allowing us to study a more extensive time series of baroclinic transport derived from upper ocean temperature sections. From $18 \mathrm{XBT}$ transects of the $\mathrm{ACC}$, the average baroclinic transport, relative to $2500 \mathrm{dbar}$, is estimated at $90 \pm 2.4 \mathrm{~Sv}$. This estimate is comparable to baroclinic transport values calculated from CTD data. We then extend the baroclinic transport time-series by applying an empirical relationship between dynamic height and cumulative baroclinic transport to weekly maps of absolute dynamic topography derived from satellite altimetry, between 14 October 1992 and 23 May 2007. The estimated mean baroclinic transport of the ACC, obtained this way, is $84.7 \pm 3.0 \mathrm{~Sv}$. These transports agree well with simultaneous in-situ estimates (RMS difference in net transport $=5.2 \mathrm{~Sv}$ ). This suggests that sea level anomalies largely reflect baroclinic transport changes above $2500 \mathrm{dbar}$.
\end{abstract}

Keywords: Baroclinic transport; Antarctic Circumpolar Current; satellite altimetry. 


\section{Introduction}

37 The Antarctic Circumpolar Current (ACC) flows, uninterrupted, around Antarctica. It is the 38primary means by which water, heat and salt are transported between the Atlantic, Indian and Pacific 39Oceans. These exchanges provide a vital mechanism for the global Meridional Overturning Circulation 40(MOC), which regulates the global climate system [Gordon, 1986; Rintoul, 1991; Sloyan and Rintoul, 412001; Rintoul, 2006; Speich et al., 2001; 2007a]. The spatial and temporal coverage of hydrographic 42 measurements in the Southern Ocean remain severely limited by the logistic difficulty of sampling in this 43remote and harsh environment. This results in a poor understanding of the physical and dynamical 44 processes that control the variability of the ACC and its influence on the MOC. The ACC is largely 45 influenced by the oceanographic regimes that extend beyond its northern and southern borders. This is 46particularly true south of Africa where the ACC flows alongside the Agulhas Current system to the north. 47This system is regarded as one of the strongest western boundary currents in the world. Agulhas Rings, 48shed by the Agulhas Retroflection, are the primary means driving exchanges of water between the Indian 49and Atlantic Oceans [Byrne et al., 2006]. This leakage plays an important role on the MOC [Gordon, 1985; 501986; Weijer et al., 1999; Speich et al., 2007a]. The influence of the Agulhas Retroflection and associated

51ring shedding largely determines the latitudinal extent of the Subtropical Front south of Africa [Belkin and 52Gordon, 1996; G. Dencausse, pers. comm.], and, therefore, the northern limit of the ACC (Figure 1). South 53of the ACC, in this same sector of the Southern Ocean, the Weddell Gyre constitutes the largest cyclonic 54 circulation regime in the Southern Ocean. The Weddell Gyre transfers heat and salt from the ACC to the 55Antarctic Continental shelves, where deep and bottom waters are formed [Orsi et al., 1993].

56 The GoodHope project launched in early 2004 [www.ifremer.fr/lpo/speich/GOODHOPE.htm; 57Ansorge et al., 2004; Speich et al., 2007a] aims to establish an intensive monitoring programme that will 58 provide detailed information on the varying physical structure and volume flux of water masses and of the 59 associated mass, heat and fresh-water fluxes between the Atlantic and Indian sector of the Southern Ocean. 60Sustained observations along the GoodHope cruise track provide the means to monitor the vertical thermal 61 and salinity structure and variability of the ACC and its associated fronts. More extensive monitoring has 62been underway, since the 1970s, in Drake Passage [Sprintall et al., 1997], and in the Australian and the 63New Zealand 'chokepoints' [Rintoul et al., 1997; Budillon and Rintoul, 2003]. The deployment of XBTs by 64research and merchant vessels that supply the Antarctic bases provides an economical and rapid means to 65 collect ocean temperature data. Nevertheless, these data need to be complimented by full depth CTD casts, 66current observations through Acoustic Doppler Current Profilers, current meter moorings or pressure 
67inverted echo sounder (PIES) arrays in order to robustly constrain the structure and variability of mass, heat 68 and fresh-water transports through the widest 'chokepoint' of the Southern Ocean (approximately $4000 \mathrm{~km}$ 69 between Africa and Antarctica). This vast distance and lack of scientific data in this remote region make the 70task of monitoring the Southern Ocean south of Africa very challenging.

71 A major objective of the GoodHope programme is to provide sound estimates of ACC transport 72and its variability. Previous ACC transport estimates in the region of the Greenwich Meridian came from 73Whitworth and Nowlin [1987] and Legeais et al. [2005]. Using CTD casts from the AJAX expedition, 74Whitworth and Nowlin [1987] estimated the baroclinic transport, relative to the bottom of the ACC, to be 75162 Sv. From three CTD sections occupied near the Greenwich Meridian the baroclinic transports were 76averaged to $144.6 \mathrm{~Sv}$, relative to the bottom, and $88.9 \mathrm{~Sv}$, relative to 2500 dbar [Legeais et al., 2005]. 77Legeais et al. [2005], following Rintoul et al. [2002], used a proxy method based on an empirical 78relationship between upper ocean temperatures and the potential energy anomaly to derive the baroclinic 79 transport of the ACC from 14 XBT sections near the Greenwich Meridian. The mean of these baroclinic 80transport estimates is $97.5 \mathrm{~Sv}$, relative to $2500 \mathrm{dbar}$, and range from $87.5 \mathrm{~Sv}$ to $109.6 \mathrm{~Sv}$.

81 In this study, we establish empirical relationships whereby dynamic height and baroclinic 82 transport of the ACC can be determined from the upper ocean mean temperature alone. These relationships 83allow us to apply remotely sensed sea surface height ( $\mathrm{SSH}$ ) data to the proxy techniques, thereby enhancing 84the spatial and temporal sampling resolutions. One of the direct outcomes of this method allows us to 85monitor the upper ocean ACC thermal structure and its variability through the variability of the ACC fronts 86 and SSH. These estimates are crucial in understanding the changes in the density field and its associated 87 mass, heat and fresh-water transports. Our proxy methods prove to be robust by comparing our results to 88previous classical estimates and are very useful in an ocean region where observations remain scarce. 89Indeed, our understanding of how the ACC transport varies, even at seasonal scales, is still largely 90incomplete. As the ACC is the major component of the global ocean circulation, it is especially important 91to evaluate the internal variability of this large flow system and to identify interannual and long term 92changes in its transports, as they are intimately related to the interocean exchange of mass, heat and fresh93 water. The combination of in-situ and remotely sensed data offers a powerful means to provide the first 94quantitative insight on the ACC transport variability.

95 The data used in this study are presented in Section 2. Section 3 describes the upper thermal 96structure and frontal variability between Africa and Antarctica primarily using XBT data. Detailed 97procedures and results, related to the proxy methods used to derive dynamic height data from the upper 
98ocean mean temperature alone, are explained in Section 4. In Section 5, we use the available hydrographic

99dynamic height data in the study region to derive baroclinic transport estimates of the ACC south of Africa 100and then analyse the meridional distribution of these transports in Section 6. In Section 7, transport 101estimates from satellite altimetry are discussed and compared to the CTD and XBT estimates. A time series 102of baroclinic transports, derived from satellite altimetry for the whole ACC and for each ACC front, is 103 considered in Section 8. A summary completes the paper, where we go over the main points of the study 104and give some perspectives on further exploitation of the proxy methods we have presented here.

105

1062. Data

\subsection{Conductivity-Temperature-Depth}

108 We use data from six CTD sections completed in the South-East Atlantic between November 1983 109 and October 2005. The sections provide a good coverage of the seasonal variability expected in the South110East Atlantic region because they are occupied during all seasons (Table 1). While the first four of these 111data sets come from historical observations (from 1984 to 1993), the last two of them consist of the first 112two repeats of the GoodHope transect completed by the Shirshov Institute of Oceanology, aboard the RV 113Akademik Sergey Vavilov [Gladyshev et al., 2007]. The two CTD occupations along the GoodHope line 114allow us to improve the accuracy of the baroclinic transport estimates from those already made by Legeais 115et al. [2005]. This is because the two GoodHope cruises are occupied over the same cruise track (in 116different years) and the water column was sampled with a relatively high spatial resolution (each station is 117 separated by approximately $45 \mathrm{~km}$ ). In total, we use data from 276 CTD casts (of which 232 stations lie 118within the ACC domain), which connect Cape Town to Antarctica primarily following a ground track of 119the satellite altimeters (track no. 133 of Topex-Poseidon initially, followed by Jason1) till the Greenwich 120Meridian from where the GoodHope transect continues south to the Antarctic continent (Figure 2). The 121 AJAX and A21 transects have the coarsest spatial resolution, where stations are spaced approximately 100 $122 \mathrm{~km}$ apart as opposed to a 75 and $88 \mathrm{~km}$ spacing between stations occupied by the A12 and SR2-WOCE 123 sections, respectively. The first GoodHope CTD section has a mean spacing of $43 \mathrm{~km}$, while the mean 124 station spacing for the second GoodHope CTD section is $56 \mathrm{~km}$. In most cases, tighter station spacing is 125 found over regions of dynamic or steep bottom topography. The closer spacing between the GoodHope 126CTD casts allow us to include 'snapshots' of the mesoscale structure of the flow along the whole 127GoodHope transect (the characteristic length scale of eddies and meanders is greater than $100 \mathrm{~km}$ in 128diameter). Details concerning the CTD calibration, station positions, bottle analysis, problems encountered, 
129 and sampling carried out on each cruise can be found in a series of technical reports and papers [SIO, 1985;

130Roether et al., 1990; Lemke, 1992; Gladyshev et al., 2007].

131

\subsection{Expendable Bathythermograph (XBT)}

133The XBT data, in part, originates from 13 sections completed close to the Greenwich Meridian (Figure 3), 134between 1989 and 2006, as part of German and Russian research cruises and one ferry service completed 135by the University of Cape Town. Apart from the August 1989 transect, sampling took place during summer 136months, between November and March. In addition to this, five repeat high-density XBT sections have 137been completed since February 2004 along the GoodHope cruise track, as part of the GoodHope and the 138AOML Atlantic high-density XBT programs. The ocean structure is extremely well resolved by using 139XBTs deployed at high resolution. This proves to be particularly important when studying the dynamics 140and variability of the ACC as its flow is composed of discrete and intense narrow jet-like structures 141[Sokolov and Rintoul, 2007a; 2007b].

142 During the GoodHope transects, XBTs were deployed to measure the upper ocean temperature at 143 intervals of $25 \mathrm{~km}$, increasing the frequency to $15 \mathrm{~km}$ over the frontal regions of the ACC. Most 144deployments reached a maximum working depth of the Sippican Deep Blue XBT, which is in the order of $145780 \mathrm{~m}$. The GoodHope and Alfred Wegner Institute (AWI) XBT transects are sampled with a vertical 146resolution of 2 dbar, while the section completed by the Arctic and Antarctic Russian Institute (AARI) has 147a vertical resolution of $1 \mathrm{dbar}$. The $4000 \mathrm{~km}$ transect between Africa and Antarctica was on average 148 completed within two weeks, with each section providing a roughly synoptic picture of the upper thermal 149layer in this sector of the Southern Ocean.

150 Extensive quality control procedures have been applied to the XBT data by AOML/NOAA in the 151United States. Adjacent temperature profiles were compared with each other and to the Levitus climatology 152[Levitus, 1982] in the region. Profiles were declared bad and discarded if they did not reach a minimum 153 depth of $400 \mathrm{dbar}$. When feasible and if the temperature data recovered well, 'spikes' in the profile were 154removed and edited. For more details on AOML quality control procedures, refer to Bailey et al. [1994] and 155Daneshzadeh et al. [1994].

\section{6}

\subsection{Satellite altimetry data}

1582.3.1. Sea level anomaly 
160Sea Level Anomaly (MSLA)' product from CLS/AVISO, a weekly SSH anomaly map on a $1 / 3^{\circ}$ Mercator 161 grid that incorporates T/P, Jason-1, ERS-1/2 and Envisat altimeters, was used in this study. Because the $162 \mathrm{ACC}$ is characterized by fine scale structures and variability we choose to use the "up to date" data 163 processing that makes use of all the satellite data available for each period. The satellite data, for this time 164series, are not homogeneous in number but for long periods they provide an improved resolution and data 165 accuracy compared with the classical "referenced" data set. These multi-mission gridded SSHs are 166referenced to a seven year (1993-1999) mean. For details on mapping methods and error corrections 167applied to these fields, refer to Le Traon et al. [1998], Le Traon and Ogor [1998] and Ducet et al. [2000]. 168

\subsubsection{Absolute dynamic topography}

170 The 'Maps of Absolute Dynamic Topography (MADT)' product from CLS/AVISO has the same 171 temporal and spatial resolution described in the sea level anomaly section. The MADT is the sum of the sea 172level anomaly data and a mean dynamic topography [Rio05 - Combined Mean Dynamic Topography 173(CMDT); Rio and Hernandez, 2004]. The CMDT is a combined product using in-situ measurements 174(hydrographic and surface drifter data), altimetry data and the EIGEN-GRACE 03S geoid. The CMDT is 175computed over a seven year period (1993-1999).

\section{6}

\section{Upper ocean thermal structure and frontal variability south of Africa}

178 South of Africa, the ACC flows between the South Atlantic and South Indian subtropical domains 179in the north and the eastern part of the Weddell Gyre in the south. The criteria and classical position of the 180following fronts observed in this region: the Subtropical Front (STF), the Subantarctic Front (SAF), the 181 Antarctic Polar Front (APF), the southern ACC front (sACCf) and the southern boundary of the ACC 182(SBdy) are listed in Table 2. A time sequence of six XBT sections (five repeat GoodHope occupations and 183an Antarctica - Cape Town section) between 2004 and 2006 (Figure 4), depicts the temporal and latitudinal 184 variability of the upper ocean temperature structure in the Atlantic sector south of Africa.

185 Significant thermal variability is produced in the form of mesoscale structures: eddies, meanders 186and narrow, intense horizontal temperature gradients corresponding to the jet-like structure of the ACC 187[e.g., Sokolov and Rintoul, 2007a]. An almost continual presence of eddies are found in the northern 188domain of the GoodHope section (located between $34-39^{\circ} \mathrm{S}$ ). These features are spawned at the Agulhas 189Current Retroflection, where large Agulhas Rings detach from the Agulhas Current and spin into the 
190Atlantic Ocean [Duncombe Rae, 1991; Lutjeharms, 1996; de Ruiter et al., 1999]. SSH and RAFOS float

191data illustrate this region as a 'cauldron' of turbulent mesoscale activity, which may directly influence the 192stability and continuity of the STF south of Africa [Belkin and Gordon, 1996; Boebel et al., 2003]. For this 193reason we question the use of the STF as a northern delimiter of the ACC in Section 7.

194 A weekly time series of the MADT data shows that Agulhas Rings propagate towards the south195 west and cross the GoodHope transect, between $39-42^{\circ} \mathrm{S}$, on approximately $1-2$ occasions per year. 196Agulhas rings further complicate the process of defining the STF because they transfer subtropical water

197signatures into the ACC realm. Furthermore their anticyclonic rotation result in large transport reversals in 198the ACC [Richardson, 2007; Gladyshev et al., 2007; refer also to Section 6]. We identify these features 199using MADT data and back-track their trajectories to confirm their point of origin is within the Agulhas 200Current Retroflection (Figure 5). The centre of an Agulhas Ring is marked by a black circle on Figure 5. 201During October, 19, 2005, the feature can be seen propagating, in a west-southwest direction. By 202December, 7, 2005, the western limit of the feature has crossed the GoodHope transect (dashed line), at 203approximately $40.5^{\circ} \mathrm{S}$. The fifth GoodHope XBT transect (Figure 4e) crosses the same feature on 204December, 5, 2005. Only the western edge of the ring is encountered. As a result of the ring being only 205clipped during the December 2005 transect, the thermal signal of the XBT data appears to be less dominant 206than the January 2005 transect, which bisected a larger proportion of a ring at $\sim 42^{\circ} \mathrm{S}$ (Figure $4 \mathrm{c}$ ). In 207addition, an Agulhas Ring is located in the Subantarctic Zone (SAZ), in the December 2005 section (Figure 2084e). The temperature sections, where these features are located, reveal a warming of the waters to $\sim 700 \mathrm{~m}$, 209 with surface temperatures ranging from $19.0^{\circ} \mathrm{C}$ (January 2005) to $15.5^{\circ} \mathrm{C}$ during the December 2005 210occupation. The Agulhas Ring, seen in January 2005 causes a strong subsurface meridional temperature 211 gradient between $<8^{\circ} \mathrm{C}$ to $>13^{\circ} \mathrm{C}$ over a distance of $<60 \mathrm{~km}$. The diameter of the warm core eddy, defined 212 by the maximum horizontal temperature gradient $(\Delta \mathrm{T} / \Delta \mathrm{x})$ at $200 \mathrm{~m}$, is approximately $170 \mathrm{~km}$. Even though 213 this constitutes a strong warm anomaly, for this region, it does not seem to affect the latitude of the SAF at $21444.22^{\circ} \mathrm{S}$, but rather it strengthens the temperature gradient across the front. In contrast, due to the absence 215 of warm or cold mesoscale features in the remaining sections, the horizontal temperature gradient, between $21641-44^{\circ} \mathrm{S}$, decreased at a steady rate, without large temperature fluctuations. 
The latitude of the ACC fronts for the six XBT transects ${ }^{1}$ are shown in Figure 6 (during three of

218the GoodHope transects the SBdy was not reached so we do not include it in our present discussion). The 219XBT-inferred positions of the ACC fronts are generally found slightly south of the traces by Orsi et al. 220[1995]. The only discrepancy comes from the path of the SAF, where Orsi et al. [1995] show the front to 221 steer south $\left(\sim 47.6^{\circ} \mathrm{S}\right)$ of Meteor Rise, located at approximately $47^{\circ} \mathrm{S}, 7^{\circ} \mathrm{E}$. The XBT and CTD sections, 222described in this study, which cross Meteor Rise, show that the SAF is, on all occasions, located to the 223 north of this rise in bathymetry.

224 The sequence of frontal latitudes (Figure 6) reveals a southward shift in both the SAF and APF, at 225least during the spring and summer months. Between 2004 - 2006, the SAF moved $1.16^{\circ}(130 \mathrm{~km})$ 226southward while the APF shifted $2.65^{\circ}$ (294 km). For the last three sections (between October 2005 and 227February 2006) some of the southward signal could be induced by seasonal warming of the upper thermal 228layer between spring and the late summer months. This is suggested by the temperature anomaly sections 229 for each of the XBT realizations (Figure 7). The three sections, between October 2005 and February 2006, 230 shows that the temperature anomaly, in the upper $150-200 \mathrm{~m}$ layer, adjusts from $<-1{ }^{\circ} \mathrm{C}$ to $>1{ }^{\circ} \mathrm{C}$. Taking the 231latitudes of the SAF and APF for two February months (2004 and 2006), a southward movement in these 232 two fronts is evident and corresponds to a warmer upper ocean state. The comparison is only made over 233two years, so it is likely that this large southward shift in the fronts is part of the short-term variability 234experienced in the region. In order to understand how much of this southward movement forms part of 235long-term southward trend, we will need a greater ensemble of data. Nonetheless, it is important to note 236that Gille [2002] has analysed temperature data from Lagrangian floating platforms to show that the 237Southern Ocean, and in particular the ACC, has warmed by $0.17^{\circ} \mathrm{C}$ since the $1950 \mathrm{~s}$. A possible explanation 238is the $50 \mathrm{~km}$ southward shift in the ACC. More recently, Cai [2006] has shown a trend in the positive wind 239stress curl (1978 and onward from NCEP/NCAR reanalysis), induced by Antarctic ozone depletion. This 240trend drives an intensifying, southward shifting of the Southern Ocean super-gyre circulation [Speich et al. 2412002; 2007b]. It is suggested that the trend in winds and related ocean circulation leads to a greater influx 242of warm water to the south in all three oceans, and contributes to an increased rate of warming in the polar 243region. This may explain the southward shift in the ACC fronts as observed over a short period here, and 244over a longer period, as observed by Gille [2002].

$10^{1}$ The February 2006 section does not follow the GoodHope cruise track and, therefore, some spatial 11 differences occur. However, variability in the altimeter SSH field is small $(<3 \mathrm{~cm})$ for the latitudinal bands 12of the SAF and APF (between February 2004-2006). This reveals that no significant change in the XBT13derived frontal positions results from the distance between the two sections. 
245

2464. Dynamic heights from XBT data

247 Rintoul et al. [1997] have shown that a tight correlation exists between the average upper ocean 248temperature and dynamic height south of Australia. Furthermore, Rintoul et al. [2002] suggest that across 249the ACC the T-S curve is stable enough to estimate dynamic heights using temperature data alone. In the 250present study we show that this correlation exists also in the ACC region south of Africa $(r=0.95$, 251 significant at the $95 \%$ level). This relationship proves to be extremely useful because XBT data, which is 252 limited to only the upper $800 \mathrm{~m}$, can be used to derive dynamic heights at the surface. To test this 253relationship, several average temperatures within pressure ranges were assessed (e.g. 100-200 dbar, 254300-400 dbar, 100-600 dbar, 600-700 dbar and 0-600 dbar). The strongest correlation exists when utilizing 255 the average temperature between 0-600 dbar and the dynamic height at the surface (relative to $2500 \mathrm{dbar}$ ). 256Moreover, the 0-600 dbar level was best suited to maximise the data available, instead of extending the 257level to 700 or 800 dbar. Figure 8 shows the empirical relationship between the temperature averaged 258 between 0-600 dbar and the dynamic height at the sea surface, relative to $2500 \mathrm{dbar}$, using data from the six 259CTD sections completed in the Atlantic sector south of Africa (see Figure 2). Four of these CTD sections 260were used because they were sampled in adjacent areas of the GoodHope transect, while the remaining two 261CTD sections were occupied along the GoodHope transect. The fact that the sections are not sampled in 262 precisely the same location has no significant impact on deriving dynamic height using these proxy 263 methods. This is because the upper ocean average temperature is a proxy for a streamline of the ACC and 264we assume that conservation in the streamline will occur to some extent upstream and downstream of the 265GoodHope transect.

266 Although the CTD sections were occupied in different seasons, the data collapse onto a single 267 curve, confirming that this relationship is stable for this region of the Southern Ocean. The shape of the 268 curve, between approximately $4-7^{\circ} \mathrm{C}$, generally reflects the meridional variation of temperature from $\sim 46^{\circ} \mathrm{S}$ 269 to $42^{\circ} \mathrm{S}$. The drop in dynamic height below $4{ }^{\circ} \mathrm{C}$ results in a steep dynamic height gradient, which is caused 270primarily by the southward increase in upper ocean salinity (34.3 to $34.7 \mathrm{psu}$ ) and fall in meridional ocean 271 temperature between $46^{\circ} \mathrm{S}$ and $55^{\circ} \mathrm{S}$. The larger scatter of points, where temperatures exceed $7^{\circ} \mathrm{C}$, is due to 272the influence of Agulhas Water introduced by Agulhas Rings north of the STF. The mean dynamic height 273 decline across the ACC for the six CTD sections is $1.1 \pm 0.06$ dyn $\mathrm{m}\left(1 \mathrm{dyn} \mathrm{m}=10 \mathrm{~m}^{2} \mathrm{~s}^{-2}\right)$. The northern 274and southern boundaries of the ACC are taken as the position of the STF and southern boundary (SBdy), 275respectively [from Orsi et al., 1995]. 
277 sections, to investigate their latitudinal dependence (Figure 9). The data points fall on a relatively tight 278 curve over the ACC, but diverge at the northern and southern ends. North of the ACC domain $\left(\sim 40^{\circ} \mathrm{S}\right)$, the 279 presence of a highly energetic field of anticyclonic and cyclonic eddies largely originating from the 280Agulhas Retroflection area (as already mentioned in Section 3), allows for a zonal and meridional exchange 281 of Atlantic, Indian and Southern Ocean water masses. The upper ocean thermal structure in this region is 282 thereby variable, causing the upper ocean temperature range to spread significantly. The SBdy marks the 283 frontier separating waters flowing in the ACC from those found in the cyclonic sub polar Weddell Gyre. 284Poleward of the SBdy, the gradient in dynamic height tends to zero. Two XBT sections (IX3 $3_{1}$ and IX $3_{2}$ ) 285 cross the Maud Rise, located at $65^{\circ} \mathrm{S}, 3^{\circ} \mathrm{E}$. The upper ocean average temperatures are higher than sections 286located further away from the Maud Rise (see Figure 9). Gordon and Huber [1995] note that a quasi287 stationary pool of relatively warm Weddell Deep Water (WDW) appears immediately west of the Maud 288Rise. This feature is derived from the flow of warm WDW around the flanks of Maud Rise. The rise in 289upper ocean temperature identified in the XBT data, over the Maud Rise, has a direct influence on 290overestimating the dynamic height data later on. This overestimate however does not have any bearing on 291 the dynamic heights estimated over the ACC.

292 In order to estimate dynamic height from the available XBT sections, we exploit the empirical 293 correlation, shown in Figure 8, by applying a smoothing spline to the data. Fifth and eighth order 294polynomial fits were also tested and applied to the data. However, the smoothing spline provides a better 295 method for the approximation of values for this dataset. In recent years, it has been generally accepted 296[Emery and Thomson, 2001] that the smoothing spline is the most effective approximation method.

297 To assess the ability of this method to infer dynamic height from XBT temperature data, we first 298compare the actual dynamic height, relative to $2500 \mathrm{dbar}$, to the estimates predicted by the regression 299relationship for the six available CTD transects. In order to avoid bias, we withhold each of the six CTD 300section's dynamic height values from the empirical relationship, before predicting the dynamic height using 301 the temperature observations. The results and corresponding root mean square difference (RMSD) over the 302ACC domain are shown in Figure 10. The mean of the RMSD for the six CTD sections is 0.05 dyn m. The 303agreement between the two estimates is excellent and the RMSDs are small. Discrepancies between the two 304estimates are largest near the northern and southern boundaries of the ACC, where the empirical 305relationship is less tight. This is likely due to the mixing of different water masses found at the boundaries 306and where the spread of upper ocean temperature increases (as shown in Figure 9). Due to the higher spatial 
307resolution of the two CTD sections ( $\sim 50 \mathrm{~km})$, occupied along the GoodHope cruise track, mesoscale 308 features are better resolved, causing the dynamic height data to vary more than found in the remaining four 309CTD sections, that have lower spatial resolutions. The ACC fronts, especially the SAF and APF are well 310represented in the dynamic height gradients.

311 Dynamic heights are now estimated from the 18 XBT sections using the empirical relationship.

312These estimates have a marked latitudinal dependence, particularly within the ACC domain, and compare 313 closely with true dynamic heights from the CTD sections (Figure 11). Once again, the values north of the 314STF exhibit a large dispersion due to the large temperature range in the upper ocean associated with this 315region. For the purpose of this study, we focus specifically on the ACC, i.e. on the domain between the STF 316 and the currents southern boundary, where the empirical relationship is particularly stable.

317 We illustrate the dynamic height estimates for the five GoodHope repeat XBT transects in Figure 31812. The mean net dynamic height drop from the northern to the southern boundary of the ACC for the five 319XBT sections is $1.1 \pm 0.065$ dyn $\mathrm{m}$, which is the same as the mean CTD dynamic height drop off. The 320range of the dynamic height drop across the ACC is between 1.01 dyn m in February 2004 to 1.20 dyn m in 321 November 2004. This indicates a range of 0.19 dyn $\mathrm{m}$ variability over the ACC. The three inner frontal 322(SAF, APF and sACCf) positions are marked along the dynamic height profiles. Local maxima in the 323dynamic height gradient can be seen over the SAF, during the GH2 (November 2004) and GH3 (January 3242005) transects. The dynamic height drop across the APF and sACCf is well reproduced during all the 325 transects. The rise and fall in the dynamic height, between the STF and SAF, is mostly induced by the 326 presence of mesoscale eddies (i.e. Agulhas Rings) that were crossed during the first and third GoodHope 327 transects. In addition to the maximum gradient in the dynamic height over the identified 'classical' fronts, 328 we see further drops in the dynamic height. These are mostly associated with the APF and suggest that the 329 'classical' ACC fronts could be associated with additional baroclinic jets as suggested by Sokolov and 330Rintoul [2007a] south of Australia. The identification of these additional jets is explained, in more detail, in 331 Section 7.

332 The evidence shown here indicates that we can determine the Southern Ocean frontal positions 333 where large gradients in dynamic heights are encountered. This suggests the position of the fronts can be 334determined from gradients of satellite SSH.

\section{5}

\section{Baroclinic transports from XBT data}


338 second empirical relationship between dynamic height, relative to $2500 \mathrm{dbar}\left(\mathrm{DH}_{2500}\right)$, and cumulative 339 baroclinic transport, integrated northward and above the $2500 \mathrm{dbar}$ isobath $\left(\mathrm{CT}_{2500}\right)$ (Figure 13). This 340relationship is constructed using data from five of the CTD transects completed in the South-East Atlantic. 341We did not make use of the baroclinic transport data from the SR2 section, since a large proportion of the 342 stations did not reach $2500 \mathrm{dbar}$. This method has been used to derive baroclinic transports from altimeter 343 data for the region south of Australia [Rintoul et al., 2002]. Similarly to Rintoul et al. [2002], we use 2500 $344 \mathrm{dbar}$ as the reference level because it is the deepest depth that lies above the height of the mid-ocean ridge. 345 The correlation between the two variables is very tight $(r=0.98$, significant at the $95 \%$ level), meaning we 346can estimate baroclinic transports using dynamic height data. Again a smoothing spline is applied to the 347 data.

348 We evaluate the accuracy of inferring baroclinic transports from upper ocean temperature data. 349The empirically derived dynamic heights for the CTD sections were first computed using upper ocean 350temperature data by exploiting the $\mathrm{T}_{0-600}-\mathrm{DH}_{2500}$ relationship and then applying it to the $\mathrm{DH}_{2500}-\mathrm{CT}_{2500}$ 351 relationship to derive baroclinic transports. These transports were then compared to baroclinic transport 352estimates derived from the five CTD sections, relative to 2500 dbar. Resulting baroclinic transports and 353RMSDs are shown in Figure 14. The mean RMSD for the five tested sections is $6.0 \mathrm{~Sv}\left(1 \mathrm{~Sv}=10^{6} \mathrm{~m}^{3} \mathrm{~s}^{-1}\right)$. 354This RMS error between baroclinic transports is relatively high however the total end transports, cumulated 355 from south to north, compare well. The mean baroclinic transport for the five sections is $87.9 \pm 3.9 \mathrm{~Sv}$ 356compared with $\mathrm{DH}_{2500}-\mathrm{CT}_{2500}$ derived baroclinic transports, which averaged $91.5 \pm 1.2 \mathrm{~Sv}$. On average, 357 cumulative baroclinic transport values obtained from the $\mathrm{DH}_{2500}-\mathrm{CT}_{2500}$ relationship exceed CTD derived 358 baroclinic transports by $3.5 \mathrm{~Sv}$, or only $4 \%$ higher.

359 We apply this proxy method to 18 XBT sections located in close proximity to the CTD transects. 360Several XBT sections are situated further eastward of the CTD transects. These sections exhibit a poleward 361shift in the STF in this region causing the average northern ACC limit on the XBT lines to be displaced 362southward relative to the average value from the CTD transects $\left(41.8^{\circ} \mathrm{S}\right.$ versus $\left.40.3^{\circ} \mathrm{S}\right)$ [Legeais et al., 3632005]. The XBT-inferred ACC baroclinic transports (above and relative to 2500 dbar; $\operatorname{Tr}_{2500}$ ) range from 36485.2 Sv to $94.7 \mathrm{~Sv}$, with a mean of $90.0 \pm 2.4 \mathrm{~Sv}$. This is only $2.1 \mathrm{~Sv}$ (or $2.3 \%$ ) higher than the $87.9 \pm 3.9$ $365 \mathrm{~Sv}$ average from the CTD sections. Figure 15, shows the baroclinic transport for the five repeat GoodHope 366sections and the Antarctica-Cape Town (AA-CT) section between February 2004 and February 2006. 367Differences in baroclinic transport, at each station pair, are represented by the stems. Large increases in net 
368 baroclinic transport occur over the main fronts of the ACC. The substantial increase and then decline in 369 baroclinic transport near the northern end of the GH3 section is as a result of the intense Agulhas Ring that 370 was crossed. These baroclinic transport estimates are biased towards the summer months when sampling 371 primarily occurred.

372 There is no clear inter-annual pattern in net baroclinic transport. The net baroclinic transport does, 373 however, tend to increase during the mid to late summer months when compared to sections completed in 374the early summer/spring months of the same season. The temperature sections show that the isotherm 375 gradients steepen as the seasonal progression warms the upper ocean layers. This increases the horizontal 376 gradient in the dynamic height, which in turn intensifies the eastward baroclinic flow. The temperature at 377 the southern end of the section is relatively constant with time, and, therefore, an increase in baroclinic 378transport tends to correspond to the presence of higher temperatures (and temperature gradients) in the 379northern domain of the ACC.

380 The mean XBT baroclinic transport estimate, made here, is $7.5 \mathrm{~Sv}$ lower than that measured by 381Legeais et al. [2005]. Our empirical relationships are constructed, partially, using the South-East Atlantic 382historic CTD sections used by Legeais et al. [2005] however we include two additional recent repeat CTD 383 sections conducted along the GoodHope cruise track. The historic CTD sections are occupied at a lower 384spatial resolution and are not located along the GoodHope cruise track, which may, in part, be the cause of 385the final transport disparity. The GoodHope CTD sections do display net baroclinic transport estimates that 386are 4 Sv less than the historic CTD estimates. Additionally, thermal changes in the upper ocean layers, 387incurred during the temporal gap (9-18 years) between the recent and the historic CTD occupations, may 388lead to the transport differences between the two studies.

389 The average of the bottom referenced transport for four CTD sections is $145.0 \pm 9.4 \mathrm{~Sv}$. Due to the 390fact that CTD casts did not reach the bottom in the majority of the stations comprising the second CTD 391 occupation of the GoodHope cruise track, no baroclinic transports relative to the bottom could be obtained 392 for this section. The ratio between the baroclinic transport above $2500 \mathrm{dbar}$ and to the bottom is almost 393 constant and averages approximately $0.62 \pm 0.055$. This ratio proves to be a useful parameter to estimate 394the full depth baroclinic transports ( $\operatorname{Tr}_{\text {bottom }}$ ) from XBT-inferred transports at $2500 \mathrm{dbar}$. When applying the $39562 \% \operatorname{Tr}_{250} / \operatorname{Tr}_{\text {bottom }}$ ratio, the bottom XBT-inferred ACC baroclinic transport ranges between 139 and $153 \mathrm{~Sv}$, 396with a mean of $145 \pm 3.9 \mathrm{~Sv}$, for the 18 XBT crossings. These estimates agree with those obtained by 397Legeais et al. [2005], who use the I6 CTD section conducted along $30^{\circ} \mathrm{E}$, in addition to the three historic 398CTD sections conducted in the South-East Atlantic, to derive bottom referenced transports form XBT data. 
399This ratio has also been observed in other regions of the ACC. Along the SR1 transect in Drake Passage the 400ratio is found to be $67.6 \pm 1.3 \%$ [Sokolov et al, 2004] for four CTD occupations or $0.60 \pm 0.02$ for six CTD 401occupations [A. C. Naviera Garabato, pers. comm.]. In a study by Rintoul et al. [2002] the ratio is $65.8 \pm$ 4022.1\% for six CTD occupations of the SR3 transect south of Tasmania.

403

\section{Meridional baroclinic transport distribution}

405 We now present results on the distribution of baroclinic transport over the meridional extent of the 406GoodHope section and show the contribution of transport within each frontal domain. The latitudinal distri407bution of the across section cumulated baroclinic transport for each repeat XBT section is shown in Figure 40816. It is evident that throughout the sections there are anomalous periods of westward flow over small spa409tial ranges. The most prominent of these westward flows are located at the northern end and can be attrib410uted to Agulhas Rings (refer to Section 3). This occurs during the third and fifth GoodHope transects, 411where eddies were identified in the temperature sections (refer to Figure 4). The most prominent of these 412 was crossed during the third GoodHope transect and which produces large opposing baroclinic transports of $41334 \mathrm{~Sv}$ westward at $41.5^{\circ} \mathrm{S}$ and $46 \mathrm{~Sv}$ eastward at $42^{\circ} \mathrm{S}$. The magnitude of these transports supports the view 414that this feature is an Agulhas Ring, which has invaded the northern part of the ACC. Similar transport fea415tures have been recorded by surface drifters and subsurface floats (at approximately $800 \mathrm{~m}$ depth) in the re416gion of $41^{\circ} \mathrm{S}$ [Richardson, 2007].

417 The mean baroclinic transport, for five GoodHope XBT transects, has been divided into half a 418degree latitudinal bands over the ACC extent (Figure 17a). Again, it is evident that the mean flow at the 419 northern end of the section (north of $42^{\circ} \mathrm{S}$ ) is found to have a strong mean westward flow. The mean 420 westward flow north of $42^{\circ} \mathrm{S}$ is $6.1 \mathrm{~Sv}$. Two broad peaks of eastward baroclinic transport are found 421 between the latitudinal ranges of the SAF and APF (arrow ranges in Figure 17). The local maximum in 422eastward flow at the $52.5^{\circ} \mathrm{S}$ band is associated with the sACCf. There is little mean additional eastward 423baroclinic flow ( $<1 \mathrm{~Sv}$ ) south of the sACCf and at the SBdy.

424 The meridional distribution of variability in the baroclinic transport (Figure 17b) is the highest in 425the region north of $\sim 42.5^{\circ} \mathrm{S}$ due to the east-west fluctuations in flow associated with the meandering STF 426and intruding Agulhas eddies. In this region, the standard deviation exceeds $12 \mathrm{~Sv}$. Large standard 427deviations are also found over the SAF, SAZ and the APF and may reflect either meridional shifts in the 428 frontal positions, changes in current strength, and/or eddy genesis and activity. This was similarly shown to 429 be the case along the SR3 and SURVOSTRAL sections completed south of Tasmania [Rintoul et al., 2002]. 
430South of $51^{\circ} \mathrm{S}$, the variability is, as expected, substantially less (standard deviations less than $3 \mathrm{~Sv}$ ), where 431 the gradient in dynamic height, over the southern most ACC fronts (sACCf and SBdy), is substantially less 432than those to the north (SAF and APF), therefore, transport variations in these fronts constitute lower 433standard deviations.

434 The baroclinic transports associated with the three inner ACC fronts (SAF, APF and sACCf), and 435their contribution to the net ACC baroclinic transport are calculated for each GoodHope transect and 436displayed in Table 3. This was done by accumulating the baroclinic transport between the point where the 437 baroclinic transport was found to be zero or flowing westward, to the south and north of the axial front 438position. This allowed us to estimate the baroclinic transport directly related to the position of the front, 439located using the temperature criteria of Orsi et al. [1995]. The integration limits are indicated on Figure 15 440for each of the three inner ACC fronts. The XBT-inferred frontal contributions largely match those deduced 441 from the CTD sections. The contribution from the SAF and sACCf for the XBT-inferred baroclinic 442 transports are $5.4 \%$ and $4.5 \%$ less, respectively. An overwhelming fraction (72\%) of the net ACC 443 baroclinic transport is accounted for by the three inner ACC fronts of which the SAF and APF dominate 444 with a $32 \%$ and $28 \%$ contribution, respectively. This emphasises the key role the fronts play in determining 445the total baroclinic transport of the ACC.

446 Legeais et al. [2005], reveal that the sACCf contributes more to the net ACC transport (21\%) than 447this study shows (11\%). Legeais et al. [2005], make use of polynomial fits to estimate the baroclinic 448transport from XBT data. This type of fitting is significantly less precise at following the undulations in 449dynamic height linked to each front, which may be responsible for over-estimating the contribution made 450by the sACCf. In addition, the dynamic height gradient from XBT data obtained before 2004 seems to be 451 somewhat greater between $52-55^{\circ} \mathrm{S}$, than the most recent XBT data (see Figure 11). This would, in part, be 452responsible for the higher sACCf transport contributions made by Legeais et al. [2005].

453 Both the SAF and APF are primarily responsible for the variability associated with the total 454transport of the ACC. These two fronts have large baroclinic transport ranges, which exceed $20 \mathrm{~Sv}$ (SAF: 45521.7-42.9 Sv; APF: 15.9-34.4 Sv), and their standard deviations are 8.8 Sv and 7.4 Sv (or 9\%), respectively. 456The transport contribution of the STF and SBdy constitutes only a small fraction of the total transport, with 457each front contributing $4.4 \%$ and $1.3 \%$, respectively. A large proportion of the remaining $22 \%$ of the total 458baroclinic transport may be accounted for by additional ACC jets, which are not taken into account when 459using the integration method used in this section. There are instances when a front appears to be separated 460into two or more branches of flow. The first GoodHope XBT transect provides such an example. The 
461 transports associated with the APF seem to be split into two distinct jets. One of these is located over the 462temperature front $\left(\sim 49^{\circ} \mathrm{S}\right)$ and the other at $\sim 50^{\circ} \mathrm{S}$, with a region of westward flow in-between the two 463eastward flowing jets. These additional transport jets are discussed in more detail in Section 7.

464

\section{Baroclinic transports inferred from satellite altimetry data}

466 An aim of this paper is to show that baroclinic transport estimates of the ACC, at a substantially 467improved temporal resolution, can be achieved. Hydrographic data are collected in the Southern Ocean 468primarily in the summer months, which creates the risk of aliasing high frequency variability. Annual XBT 469and CTD 'snapshot' sampling are not frequent enough to resolve the substantial ACC baroclinic transport 470variability that can be expected at smaller temporal scales. A continuous time series of absolute dynamic 471 topography (ADT), at weekly intervals, between 1992-2007, is created. This is done by adding the altimeter 472sea level anomalies (multi-mission gridded SSH product from AVISO; see Section 2.3.1) to the mean 473 surface dynamic height, relative to $2500 \mathrm{dbar}$, calculated from two CTD and five repeat GoodHope XBT 474sections. The gradient of the ADT compares closely with the CTD (Figure 18) and XBT dynamic height 475 gradients. The ADT product is somewhat 'smoother' than the hydrographic dynamic heights and in some 476cases mesoscale features are less well resolved. The hydrographic dynamic height estimates are relative to 4772500 dbar and include only the baroclinic signal above this level. The altimeter derived ADT, however, 478may reflect changes in the density field below 2500 dbar. Differences between the ADT and hydrographic 479dynamic heights may, therefore, in part originate from the baroclinic field below $2500 \mathrm{dbar}$, and the 480barotropic field. Without an accurate estimate of the geoid, we are unable to separate the baroclinic and 481 barotropic components of the satellite altimeter measurements. The differences may also reflect temporal 482and spatial sampling discrepancies, mapping errors and tides which have not been entirely removed from 483the altimeter signal, as well as sampling errors incurred in attaining the CTD and XBT data. Similarly, this 484 was the case when SSH anomalies, inferred from CTD and altimeter measurements, were compared south 485of Australia [Rintoul et al., 2002]. Despite these factors, hydrographic estimates of dynamic height and the 486ADT are very similar (mean RMSD is 0.063 dyn $\mathrm{m}$ ). This suggests that the ADT largely reflects baroclinic 487 changes in the upper $2500 \mathrm{~m}$ of the water column.

488 Before we attempt to estimate the baroclinic transports from the full time-series of ADT data, we 489explain the method of defining the ACC spatial limits and ACC fronts, using satellite altimeter products. 490Given that the ACC, south of Africa, is unbounded by any continental landmasses, it has an open ocean 491current structure. This becomes an advantage when estimating baroclinic transports using satellite altimetry 
492products because no flow is omitted that occurs too close to coastal areas where altimeter data becomes 493unreliable due to tidal errors. This problem was encountered by Rintoul et al. [2002] south of Tasmania, 494where the flow between $45^{\circ} \mathrm{S}$ and the Tasmanian coast was excluded due to near-coast altimeter 495 limitations.

496 More recently, high resolution hydrographic and satellite sampling have revealed that the ACC 497 consists of multiple branches or filaments, which merge and split and vary in intensity, along the 498circumpolar course [Hughes and Ash, 2001; Sokolov and Rintoul, 2007a; 2007b]. Analysis of the altimeter499derived surface velocity magnitude $\left(\sqrt{ }\left(u^{2}+v^{2}\right)\right)$ and the MADT along the second GoodHope transect 500(Figure 19a) makes it clear that more than one velocity jet exists per ACC front. The highest gradients in 501 the MADT are, as expected, located over the main velocity jets, identified by the vertical solid grey lines in 502Figure 19a. We supplement this with high resolution in-situ temperature data (Figure 19b) whereby CTD 503 and XBT temperature data are combined to better resolve the finer horizontal thermal gradient found over 504the velocity jets identified in Figure 19a. The high resolution temperature data reveals that the velocity jets, 505identified in Figure 19a, associate closely with regions of strong thermal gradients. This is especially the 506case with the dominant velocity jets of the SAF and APF. This suggests we can determine the multiple jet 507 structure of the ACC using high resolution temperature sections south of Africa, in addition to that already 508undertaken in a study south of Australia [Sokolov and Rintoul, 2007a]. A time series of altimeter-derived 509surface velocity magnitude and MADT along the GoodHope transect is presented in Figure 20. The isolines 510 of MADT (thin black lines) closely follow the surface velocity magnitudes of the main ACC jets (surface 511 colour plot). This means we can, with accuracy, follow specified isolines of MADT to locate the 512 boundaries between each of the ACC fronts, except that of the STF. South of Africa, the STF experiences 513 considerable spatial variability induced by the presence of eddies (see Section 3). This provides us with 514difficulty in defining the northern limit of the ACC using satellite altimeter data when we do not have 515 information of the vertical thermal or salinity structure, provided by in-situ hydrographic sections. Figure 51620 confirms that there are no consistent surface velocity jets or isolines of MADT to use to track the limits 517 of the STF, but rather episodic surface velocity maxima consistent with the presence of eddies and front 518 meandering. This forces us to limit the northern domain of the ACC to the northern boundary of the SAF 519 when we use satellite altimeter data alone. The boundaries between each ACC front are overlaid onto the 520surface velocity magnitude and MADT data, in Figure 20, using thick black lines. The isolines of MADT, 521 used to define the front boundaries, are given as follows: northern limit of the SAF $=1.35$ dyn $\mathrm{m}$, SAF$522 \mathrm{APF}=0.94$ dyn $\mathrm{m}$, APF-sACCf $=0.31$ dyn $\mathrm{m}$, sACCf-SBdy $=0.0$ dyn $\mathrm{m}$, southern limit of the SBdy $=$ 
523-0.13 dyn m. The northern limit of the SAF and the limit between the SAF and APF experience the highest 524latitudinal variability $\left( \pm 0.79-0.85^{\circ}\right)$, while the limits of the sACCf and the SBdy experience the least 525latitudinal variability $\left( \pm 0.35-0.38^{\circ}\right)$. It must be noted that on certain occasions (late $1992,2000,2001$, 5262003 and 2005), the SBdy domain is invaded by sea-ice. During these short periods, we locate the southern 527limit of the SBdy as the mean location during the 14 year time series of latitudes. The mean position and 528 associated standard deviations can be found in Table 4 .

529 We use the empirical relationship between dynamic height and cumulative baroclinic transport to 530estimate the baroclinic transport of the ACC (relative to 2500 dbar) from the ADT data. To test this 531approach, we compare the baroclinic transport estimated from the ADT data and from five XBT 532occupations along the GoodHope track (Figure 21). Both the transports and the form of the two curves are 533 well reproduced. The accumulation of baroclinic transport over the SAF and APF is particularly well 534represented. The station pair differences are generally less than $8 \mathrm{~Sv}$ but increase over sections that have a 535low station density. Sections with largely spaced stations cause more abrupt changes in the dynamic height 536over latitude (specifically the third GoodHope XBT section; Figure 21d). The mean RMSD between the 537two transport estimates is $7.1 \mathrm{~Sv}$ and $10.1 \mathrm{~Sv}$ for the CTD and XBT sections, respectively. Near the fronts 538(namely the SAF and APF), the ADT deduced baroclinic transport gradient is greater (i.e. greater transport 539 gains with latitude). This may, in part, reflect the deep structure of fronts, which extend closer to the sea 540floor than the rest of the ACC regime, and which are responsible for a significant proportion of the ACC's 541 net baroclinic transport (see Section 6). Other differences between the ADT and hydrographically derived 542 baroclinic transports may be due to deep baroclinic flow (>2500 dbar), and mapping errors and tides, which 543have not been removed from the altimeter signal. The difference between the two curves may also be 544attributed to the barotropic component of the flow captured in the altimeter signal and which is reproduced 545in the ADT product. We are unable to accurately estimate the contribution the deep baroclinic flow, 546mapping errors and tides have on the dynamic height and transport residuals. We, therefore, are not able to 547estimate the barotropic component of the transport found in the altimeter signal. In recent times, there has 548been slow progress made in determining the barotropic flow of the ACC. A significant contribution to 549determining the absolute transport structure of the ACC will be made once we have the ability to measure 550the barotropic component in the satellite altimetry data.

\section{1}

\section{Continuous time series of net ACC baroclinic transport}


The ADT is used to estimate a 14 year continuous time-series of baroclinic transport, relative to 5542500 dbar, over each front and the whole ACC extent (Figure 22; Table 5) by exploiting the empirical 555relationship in Figure 13. The baroclinic transports are cumulated for each of the fronts, using the limits 556defined in Section 7, and between the southern limit of the SBdy and the northern limit of SAF for the 557whole ACC sector. The time series extends, at weekly intervals, between October, 14, 1992 and May, 23, 5582007. The combined transport contribution is only $1.8 \pm 0.8 \mathrm{~Sv}$ for the SBdy and $8.7 \pm 2.2 \mathrm{~Sv}$ for the 559sACCf. The SAF and APF are responsible for a much higher mean transport contribution. The SAF and 560APF contribute $33.3 \pm 3.1 \mathrm{~Sv}$ and $40.9 \pm 2.4 \mathrm{~Sv}$, respectively. The mean baroclinic transport estimate 561 (relative to $2500 \mathrm{dbar}$ ) for the ACC is $84.7 \pm 3.0 \mathrm{~Sv}$. This is on average $2.8 \mathrm{~Sv}$ lower than the mean 562 baroclinic transport estimate inferred from the XBT data. This 'missing' transport can largely be attributed 563to the fact that we limit the cumulated transports to the northern limit of the SAF and not to the STF, as was 564done with the hydrographic derived baroclinic transports.

565 The SAF and APF are characterised by high frequency transport variability when compared to the 566sACCf and SBdy. The dynamic height gradient over the SAF and APF is considerably larger than the 567 sACCf and SBdy. This means that changes in the dynamic height gradient over the southern most fronts 568leads to smaller transport variations. Additionally, a portion of the transport variability may be associated 569 with the latitudinal variability of the front limits. The transport contribution by the APF is, on average, 7.6 570Sv higher than the SAF. This is in contrast to the frontal contributions made by the XBT-inferred transport 571 estimates. In order to avoid subjectivity, we only associate the transport contribution located either side of 572the axial front location from the XBT-inferred transports (see Section 6). This may, therefore, 573 underestimate the transport contributions for fronts that have multiple transport jets, which seems to be the 574 case for the APF. The SAF, on the other hand, is characterised as having one main core transport jet (and 575 two smaller transport jets), so little transport contribution is missed using the method described in Section 5766.

577 The mean latitudinal distribution and standard deviation of the baroclinic transports, between 5781992-2007, are represented in Figure 23. The SAF contains one distinct transport core located at $\sim 44^{\circ} \mathrm{S}$. 579Two small transport jets can be seen to the north and south of the main jet. These are located at $\sim 43^{\circ} \mathrm{S}$ and $580 \sim 44.5^{\circ} \mathrm{S}$. In contrast, the APF has three distinct transport jets. The most prevalent of these is located at $581 \sim 50.8^{\circ} \mathrm{S}$, followed by one at $\sim 49^{\circ} \mathrm{S}$, and the smallest jet located at $\sim 48^{\circ} \mathrm{S}$. The sACCf contains two main 582 transport jets, which cores lie at approximately $51.5^{\circ} \mathrm{S}$ and $52.5^{\circ} \mathrm{S}$, respectively. The small transport jet, 583located at $\sim 55.5^{\circ} \mathrm{S}$, is associated with the SBdy. Periodic occurrences of westerly transport are found at the 
584SAF and APF limit and in between the APF transport jets. This is likely caused by eddy shedding at the

585 front and jet boundaries. The dominant transport standard deviations are found at the main jets of each 586 front, which may reflect the meridional movement and change in current strength of these jets. The highest 587 transport standard deviations, for the region, occur at the SAF. The SAF accounts for over 50\% of the 588latitudinal transport standard deviations of the ACC. This suggests that the transport variations in the SAF 589 are responsible for a large proportion of the spatial baroclinic transport variability related to the ACC. The $590 \mathrm{APF}$ accounts for $33 \%$ of the total transport variance per latitude. This means the APF is over $35 \%$ more 591stable than the SAF, when concerning latitudinal transport variability even though the APF has a greater 592 overall baroclinic transport contribution to the ACC. The sACCf and SBdy follow suit with a contribution 593 of $14 \%$ and $3 \%$ to the total standard deviation, respectively. The front contributions to the net baroclinic 594transport and standard deviation of the ACC are summarised in Table 5.

595

\section{Summary}

597 The exploitation of data is extremely important in the Southern Ocean, where it is especially hard 598to obtain due to its isolation and hostile environment. This study demonstrates how repeat CTD sections 599allow us to derive proxy techniques to determine the variability of the ACC, using XBT and remotely 600 sensed data alone. These alternative methods are used to make accurate estimates of baroclinic transport 601 with high spatial and temporal resolution.

602 First, we showed that a close correlation exists between upper ocean temperature and dynamic 603 height. Surface dynamic heights were, therefore, derived from XBT profiles, which compared closely to the 604 'true' dynamic heights calculated from CTD data. The agreement between the two estimates were excellent 605 and differences were small (mean RMSD $<0.05$ dyn $\mathrm{m}$ ). These differences were highest towards the 606southern and northern end of the sections, where communication between several water masses containing 607different temperature and salinity signatures, was most extensive. The resulting dynamic heights showed 608 close correspondence with the location of the ACC fronts (where local maxima in gradients were 609experienced). Additionally, the dynamic height data were accurate at resolving mesoscale features evident 610in the temperature sections.

611 A similar empirical relationship between surface dynamic height and cumulative baroclinic 612 transport was used to derive, with minimal error, the baroclinic transport from all available XBT dynamic 613 height profiles. These transports were found only to be, on average, $2.3 \%$ higher than the actual geostrophic 614measurements. The ratio between $2500 \mathrm{dbar}$ and bottom referenced CTD transports was relatively constant 
615(67\%), thereby allowing us to reference the XBT baroclinic transports to full depth. The mean baroclinic 616 transport, relative to $2500 \mathrm{dbar}$, for $18 \mathrm{XBT}$ sections was $90 \pm 2.4 \mathrm{~Sv}$, while the bottom referenced 617 baroclinic transport estimate was $145 \pm 3.9 \mathrm{~Sv}$.

618 The mean distribution of baroclinic transport with latitude exhibited broad bands of eastward flow 619 associated with the three inner ACC fronts. As expected, these fronts also contributed to extensive amounts 620 of variability in the ACC flow. The most northern part of the sections displayed periods of extreme flow 621 reversals contributing to the highest amounts of transport variability. These occurrences were attributed to 622south-westward propagating Agulhas Rings, which penetrated the northern domains of the ACC along the 623GoodHope transect.

624 The ADT data, over the ACC, was created by adding SSH anomaly data to a mean surface 625dynamic height. The ADT compared closely with dynamic heights from CTD and XBT data (mean RMSD 626of 0.063 dyn m). Similarly, we applied the ADT to the empirical relationship between dynamic height and 627 cumulative baroclinic transport to obtain a 14 year time series of net baroclinic transport estimates for the 628ACC. Intense mesoscale variability, in the form of eddies propagating from the Agulhas Retroflection, 629 made it difficult to accurately define the northern limit of the ACC. Instead, we chose to cumulate the 630 baroclinic transports to the northern limit of the SAF in order to provide a more accurate account of the net 631 ACC baroclinic transport. The altimetry derived mean baroclinic transport of the ACC, relative to 2500 $632 \mathrm{dbar}$, was $84.7 \pm 3.0 \mathrm{~Sv}$. The transports estimated per front, show that the SAF and APF contribute the bulk 633 of the ACC baroclinic transport ( $88 \%)$, while the sACCf and SBdy add the remaining $\sim 12 \%$. The mean 634latitudinal distribution of the transports reveals that each front is characterised by multiple eastward 635flowing jets that together, make up the total circumpolar flow. Interestingly, the SAF was found to 636contribute over $50 \%$ of the baroclinic transport variability of the ACC, even though its net transport 637 contribution to the ACC was $9 \%$ less than the APF. The use of satellite altimetry products, to identify the 638 front limits, proves to be a valuable tool in accurately defining the role and contribution each front has in 639determining the total baroclinic transport and associated variability of the ACC.

640 As shown by Rintoul et al. [2002] and Sokolov et al. [2004], these proxy techniques are 641 appreciably promising and justify added effort to refine them further. The progression of the GoodHope 642 programme in coming years will improve these methods through supplementary hydrographic sections. 643These proxy techniques highlight the value remote sensing techniques have on monitoring the transport and 644associated variability of the ACC, in a data sparse and remote expanse, like the Southern Ocean. 
646Acknowledgments The successful completion of the hydrographic surveys would not have been possible 647 without the invaluable assistance of the captains, officers, crew and scientists of the MV S.A. Agulhas and 648RV Akademik Sergey Vavilov. We are grateful to Silvia Garzoli and NOAA/OCO for their support to 649implement the XBT deployments in high density mode, to Molly Baringer and Qi Yao for their assistance 650in the quality control of the data at NOAA/AOML, and to Steven Cook, Robert Roddy, Craig Engler and 651Jim Farrington for their logistics support with XBT deployments. S. Swart especially thanks S. Speich for 652the support during a total of eight months stay at the Laboratoire de Physique des Oceans, UBO, France and 653J.-F. Legeais for technical assistance. The work presented here is supported by the South African National 654Antarctic Programme (SANAP) and the Russian Academy of Sciences (Grant Meridian Plus \#18.17.3) 655 through the provision of funds and facilities. The authors also thank Dr A. Sokov for his effort in helping 656implement this programme and the Alfred Wegener Institute for Polar and Marine Research for the partial 657 provision of data used in this study. Lastly, we would like to thank three anonymous reviewers for their 658 comments, which helped improve the manuscript.

659

660 


\section{References}

662Ansorge, I. J., S. Speich, J. R. E. Lutjeharms, G. J. Goni, C. J. Rautenbach, W. Froneman, M. Rouault, and

663 S. Garzoli. 2004. Monitoring the oceanic flow between Africa and Antarctica. South African J. Sci., $664 \quad 101,29-35$.

665Baily, R., A. Gronel, H. Phillips, G. Meyers, and E. Tanner. 1994. CSIRO Cookbook for quality control of 666 expendable bathythermograph (XBT) data. Rep. No. 220. CSIRO Marine Laboratories, Hobart, 667 Australia. $75 \mathrm{pp}$.

668Belkin, I. M. and A. L. Gordon, 1996. Southern Ocean fronts from the Greenwich meridian to Tasmania. J. 669 Geophys. Res., 101, 3675-3696.

670Boebel, O., J.R.E. Lutjeharms, C. Schmid, W. Zenk, T. Rossby and C. Barron. 2003. The Cape Cauldron: a 671 regime of turbulent inter-ocean exchange. Deep Sea Res. Part II, 50, 57-86.

672Budillon, G. and S. R. Rintoul. 2003. Fronts and upper ocean thermal variability south of New Zealand. 673 Antarctic Science, 15, 141-152.

674Byrne, D. A., D. L. Witter, D. R. Watts, N. R. Pettigrew, C. M. Duncombe Rae, and S. Baker-Yeboah. 675 2006. Interocean heat and salt transports from the Agulhas Leakage: First results from ASTTEX. 676 Eos Trans. AGU, Ocean Sci. Meet. Suppl., 87(36): Abstract OS22C-03.

677Cai, W. 2006. Antarctic ozone depletion causes an intensification of the Southern Ocean super-gyre 678 circulation. Geophys. Res. Lett., 33, L03712, doi:10.1029/2005GL024911.

679Daneshzadeh, Y-H. C., J.F. Festa, and S.M. Minton. 1994. Procedures used at NOAA-AOML to quality 680 control real time XBT data collected in the Atlantic Ocean. NOAA Tech. Memo. ERL AOML-78, 681 NOAA Atlantic Oceanographic and Meteorological Laboratory. 44pp.

682de Ruijter, W. P. M., A. Biastoch, S. S. Drijfhout, J. R. E. Lutjeharms, R. P. Matano, T. Pichevin, P. J. van 683 Leeuwen, and W. Weijer. 1999. Indian-Atlantic interocean exchange: Dynamics, estimation and 684 impact. J. Geophys. Res., 104(C9), 20,885-20,910.

685Ducet, N., P. Y. Le Traon, and G. Reverdin. 2000. Global high-resolution mapping of ocean circulation 686 from TOPEX/Poseidon and ERS-1 and -2. J. Geophys. Res., 105, 19,477-19,498.

687Duncombe Rae, C. M. 1991. Agulhas retroflection rings in the South Atlantic Ocean: an overview. South 688 African J. Mar. Sci., 11, 327-344.

689Emery, W. J. and R. E. Thomson. 2001. Data analysis methods in physical oceanography: 2nd Edition 690 Revised. Elsevier Science. Amsterdam, 640p. 
691Gille, S. T. 2002. Warming of the Southern Ocean since the 1950s. Science, 295, 1275-1277.

692Gladyshev, S., M. Arhan, A. Sokov, and S. Speich. 2007. A hydrographic section from South Africa

693 southwestward to the southern limit of the Antarctic Circumpolar Current at the Greenwich

694 meridian. Deep Sea Res., submitted.

695Gordon, A. L. 1985. Indian-Atlantic transfer of Thermocline Water at the Agulhas Retroflection. Science $696227,1030-1033$.

697Gordon, A. L. 1986. Inter-Ocean Exchange of Thermocline Water. J. Geophys. Res., 91, 5037-5046.

698Gordon, A. L., and B. A. Huber. 1995. Warm Weddell Deep Water west of Maud Rise, J. Geophys. Res., $699 \mathbf{1 0 0}(\mathrm{C} 7), 13,747-13,753$.

700Hughes, C. W. and E. R. Ash. 2001. Eddy forcing of the mean flow in the Southern Ocean. J. Geophys. 701 Res., 106(C2), 2713-2722.

702Legeais, J. F., S. Speich, M. Arhan, I. J. Ansorge, E. Fahrbach, S. Garzoli, and A. Klepikov. 2005. The 703 baroclinic transport of the Antarctic Circumpolar Current south of Africa. Geophys. Res. Lett., 32, $704 \quad$ L24602, doi:10.1029/2005GL023271.

705Lemke, P. 1992. WHP Cruise Summary Information: A12. Tech. Rep., Alfred Wegner Institut fuer Polar 706 und Meeresforschung, Bremerhaven, Germany.

707Le Traon, P. Y., P. F. Nadal, and N. Ducet. 1998. An improved mapping method of multisatellite altimeter 708 data. J. Atmos. Oceanic Technol. 15, 522-534.

709Le Traon, P. Y. and F. Ogor. 1998. ERS-1/2 orbit improvement using TOPEX/POSEIDON: The 2cm 710 challenge. J. Geophys. Res., 103, 8045-8057.

711Levitus, S. 1982. Climatological Atlas of the World Ocean, NOAA Professional Paper No. 13, pp. 191.

712Lutjeharms, J.R.E. 1996. The exchange of water between the South Indian and South Atlantic oceans. In:

713 Wefer, G., Berger, W.H., Siedler, G. \& Webb, D.J. (Eds.), The South Atlantic: Present and Past 714 Circulation, Berlin, Heidelberg: Springer-Verlag, 125-162.

715Orsi, A. H., W. D. Nowlin, and T. Whitworth. 1993. On the circulation and stratification of the Weddell 716 Gyre. Deep Sea Res. Part I, 40, 169-203.

717Orsi, A. H., T. Whitworth, and W. D. Nowlin. 1995. On the meridional extent and fronts of the Antarctic 718 Circumpolar Current. Deep Sea Res. Part I, 42, 641-673.

719Richardson, P. L. 2007. Agulhas leakage into the Atlantic estimated with subsurface floats and surface 720 drifters. Deep Sea Res. Part I, 54, 1361-1389. 
721 Rintoul, S. R. 1991. South-Atlantic interbasin exchange. J. Geophys. Res., 96, 2675-2692.

722Rintoul, S. R., J. R. Donguy, and D. H. Roemmich. 1997. Seasonal evolution of upper ocean thermal 723 structure between Tasmania and Antarctica. Deep Sea Res. Part I, 44, 1185-1202.

724Rintoul, S. R., S. Sokolov, and J. Church. 2002. A 6 year record of baroclinic transport variability of the 725 Antarctic Circumpolar Current at $140^{\circ} \mathrm{E}$ from expendable bathythermograph and altimetry 726 measurements. J. Geophys. Res., 107(C10), 3155, doi:10.1029/2001JC000787.

727Rintoul, S. R. 2006. The global influence of the Southern Ocean circulation. Proceedings of 8 ICSHMO, 728 Foz do Iguaçu, Brazil, April 24-28, 2006, INPE, 1349-1354.

729Rio, M.-H., and F. Hernandez. 2004. A mean dynamic topography computed over the world ocean from 730 altimetry, in situ measurements, and a geoid model. J. Geophys. Res., 109, C12032, doi: $731 \quad 10.1029 / 2003 J C 002226$.

732Roether, W., M. Samthein, T. J. Muller, W. Nellen, and D. Sahrhage. 1990. Sudatlantik- Zircumpolarstom, 733 Reise Nr. 11, 3 Oktober 1989-11 Marz 1990, Meteor-Ber. 90-2. Tech. Rep., University of Hamburg, 734 Hamburg, Germany.

735SIO. 1985. Cruise Report: AJAX. Tech. Rep., Schripps Institution of Oceanography/Texas AM University, 736 USA.

737Sloyan, B. M., and S. R. Rintoul. 2001. Circulation, renewal and modification of Antarctic mode and 738 intermediate water. J. Phys. Oceanogr., 31, 1005- 1030.

739Sokolov, S., B. A. King, S. R. Rintoul, and R. L. Rojas. 2004. Upper ocean temperature and the baroclinic 740 transport stream function relationship in Drake Passage. J. Geophys. Res., 109, C05001, doi: $741 \quad 10.1029 / 2003 J C 002010$.

742Sokolov, S., and S. R. Rintoul. 2007a. Multiple jets of the Antarctic Circumpolar Current south of 743 Australia. J. Phys. Oceanogr., in press.

744Sokolov, S., and S. R. Rintoul. 2007b. On the relationship between fronts of the Antarctic Circumpolar 745 Current and surface chlorophyll concentrations in the Southern Ocean. J. Geophys. Res., 112, 746 C07030, doi:10.1029/2006JC004072.

747Speich, S., B. Blanke, and G. Madec. 2001. Warm and cold water routes of an OGCM thermohaline 748 conveyor belt. Geophys. Res. Lett., 28, 311-314. 
749Speich, S., B. Blanke, P. de Vries, S. Drijfhout, K. Döös, A. Ganachaud, and R. Marsh. 2002. Tasman 750 leakage: A new route in the global ocean conveyor belt. Geophys. Res. Lett., 29(10), 1416, doi: $751 \quad 10.1029 / 2001 G L 014586$.

752Speich, S. et al., 2007a. GOODHOPE/Southern Ocean: A study and monitoring of the Indo-Atlantic 753 connections. Mercator Newsletter, October 2007, 27, 29-41.

754Speich, S., B. Blanke, and W. Cai. 2007b. Atlantic meridional overturning circulation and the Southern 755 Hemisphere supergyre. Geophys. Res. Lett., 34, doi:10.1029/2007GL031583, 2007.

756Sprintall, J., R. Peterson, and R. Roemmich. 1997. High resolution XBT/CTD measurements across Drake 757 Passage. WOCE Newsletters 29, 18-20.

758Weijer, W., W. P. M. De Ruijter, H. A. Dijkstra, and P. J. van Leeuwen. 1999. Impact of interbasin 759 exchange on Atlantic overturning. J. Phys. Oceanogr., 29, 2266- 2284.

760Whitworth, T. and W. D. Nowlin. 1987. Water masses and currents of the Southern Ocean at the 761 Greenwich meridian. J. Geophys. Res., 92, 6462-6476.

762

763 
764Table 1. Summary of the CTD sections used in this study

\begin{tabular}{lllll}
\hline Section & Date & Ship & Institute & Chief Scientist \\
\hline AJAX & Jan. 1984 & R/V Knorr & Texas A\&M U. & T. Whitworth \\
A21 & Jan.-Mar. 1990 & R/V Polarstern & U. Bremen & W. Roether \\
A12 & May-Aug. 1992 & R/V Meteor & A.W.I. & P. Lemke \\
SR2 & Jan.-Feb. 1993 & M/V SA Agulhas & U. Cape Town & M. I. Lucas \\
GH2 & Nov. 2004 & R/V Vavilov & Shirshov & S. Gladyshev \\
GH4 & Oct. 2005 & R/V Vavilov & Shirshov & S. Gladyshev \\
\hline
\end{tabular}
765

766

767Table 2. Temperature criteria used to locate the ACC fronts, reproduced from Orsi et al. [1995]. STF is the 768Subtropical Front, SAF the Subantarctic Front, APF the Antarctic Polar Front, sACCf the southern ACC 769 front, SBdy the southern boundary of the ACC and $\theta$ is potential temperature. The classical positions of the 770ACC fronts, along the GoodHope transect, as determined by Orsi et al. [1995], are given

\begin{tabular}{lcc}
\hline Front & Temperature criteria & Classical position $\left({ }^{\circ} \mathrm{S}\right)$ \\
\hline STF & $10^{\circ} \mathrm{C}<\theta_{100 \mathrm{~m}}<12^{\circ} \mathrm{C}$ & 39.9 \\
SAF & $\theta>4-5^{\circ} \mathrm{C}$ at $400 \mathrm{~m}$, farther north & 47.6 \\
APF & $\theta<2{ }^{\circ} \mathrm{C}$ along $\theta_{\text {min }}$ at $\mathrm{z}<200 \mathrm{~m}$, farther south & 49.6 \\
sACCf & $\theta<0^{\circ} \mathrm{C}$ along $\theta_{\text {min }}$ at $\mathrm{z}<150 \mathrm{~m}$, farther south & 52.4 \\
SBdy & Southern limit of vertical maximum of $\theta>1.5^{\circ} \mathrm{C},(\sim 200 \mathrm{~m})$ & 56.1 \\
\hline
\end{tabular}

772

773 Table 3. Mean position of the three inner ACC fronts and associated contribution of each front to the XBT774derived baroclinic transport of the ACC (in Sverdrups and percentage of net ACC baroclinic transport, 775 relative to $2500 \mathrm{dbar}$ )

\begin{tabular}{lccc}
\hline Front & Mean Position $\left({ }^{\circ} \mathrm{S}\right)$ & Transport $(\mathrm{Sv})$ & $\%$ Transport of ACC \\
\hline SAF & $44.6 \pm 0.5$ & $28.8 \pm 8.8$ & $32.3 \pm 9.1$ \\
APF & $50.4 \pm 0.9$ & $24.8 \pm 7.4$ & $28.4 \pm 9.0$ \\
sACCf & $52.8 \pm 0.4$ & $9.8 \pm 5.9$ & $11.1 \pm 6.6$ \\
Total & - & 63.4 & 72 \\
\hline 76
\end{tabular}

777

778Table 4. Mean position and standard deviation of the boundaries of each front, as defined using satellite 779altimetry

\begin{tabular}{lcc}
\hline Front Boundary & Mean Position $\left({ }^{\circ} \mathrm{S}\right)$ & Standard Deviation $\left({ }^{\circ}\right.$ latitude $)$ \\
\hline STF-SAF & 43.0 & 0.85 \\
SAF-APF & 47.4 & 0.79
\end{tabular}




\begin{tabular}{lll} 
APF-sACCf & 51.9 & 0.57 \\
sACCf-SBdy & 54.9 & 0.35 \\
southern SBdy & 56.2 & 0.38 \\
\hline
\end{tabular}

780

781

782Table 5. Mean contribution of baroclinic transport by each front to the net baroclinic transport of the ACC

783 derived from satellite altimetry data (in Sv and percentage, relative to $2500 \mathrm{dbar}$ ). The contribution of each 784 front to the net transport standard deviation is given in percent.

\begin{tabular}{lccc}
\hline Front & Transport (Sv) & \% Transport of ACC & \% of total standard deviation \\
\hline SAF & $33.3 \pm 3.1$ & $39.2 \pm 2.5$ & 50.7 \\
APF & $40.9 \pm 2.4$ & $48.4 \pm 3.3$ & 32.7 \\
sACCf & $8.7 \pm 2.2$ & $10.2 \pm 2.6$ & 13.6 \\
SBdy & $1.8 \pm 0.8$ & $2.2 \pm 0.9$ & 3.0 \\
\hline
\end{tabular}




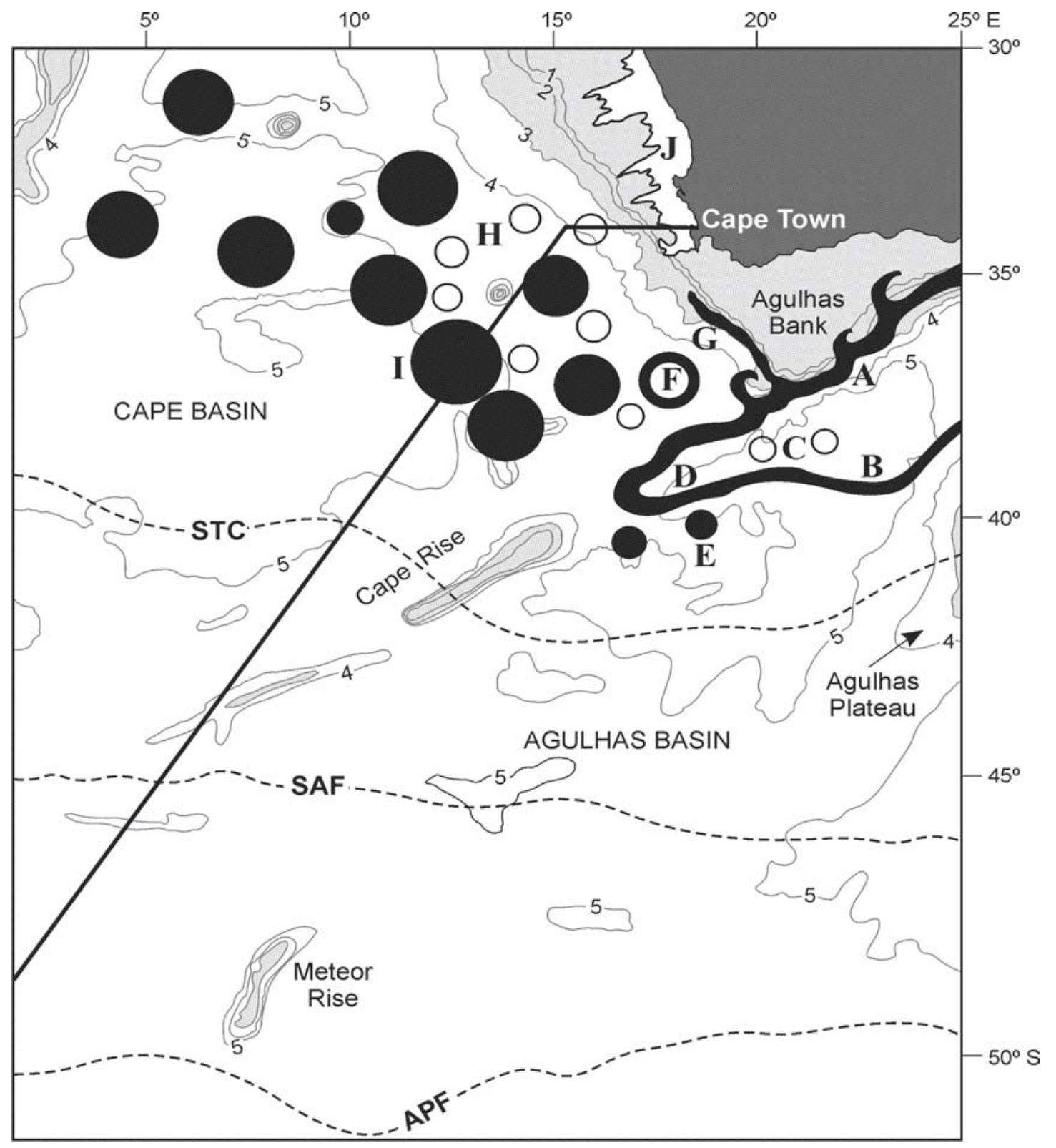

786Figure 1. A conceptual diagram of the southern Agulhas Current system. Agulhas Rings (I) and filaments 787(G) are shed at the Agulhas Retroflection (D) and are carried equatorward by the Benguela Current (H). 788The Agulhas Current retroflects forming an eastward flow (B) to the north of the Subtropical Convergence 789(STC; otherwise known as the Subtropical Front). The GoodHope transect (solid line) crosses the southern 790domains of the Benguela upwelling regime (J). The STC, SAF and APF denote the mean locations of the 791Subtropical Convergence, Subantarctic and Antarctic Polar fronts, respectively. Bathymetry contours are in $792 \mathrm{~km}$ and depths less than $300 \mathrm{~m}$ are shaded. 
793

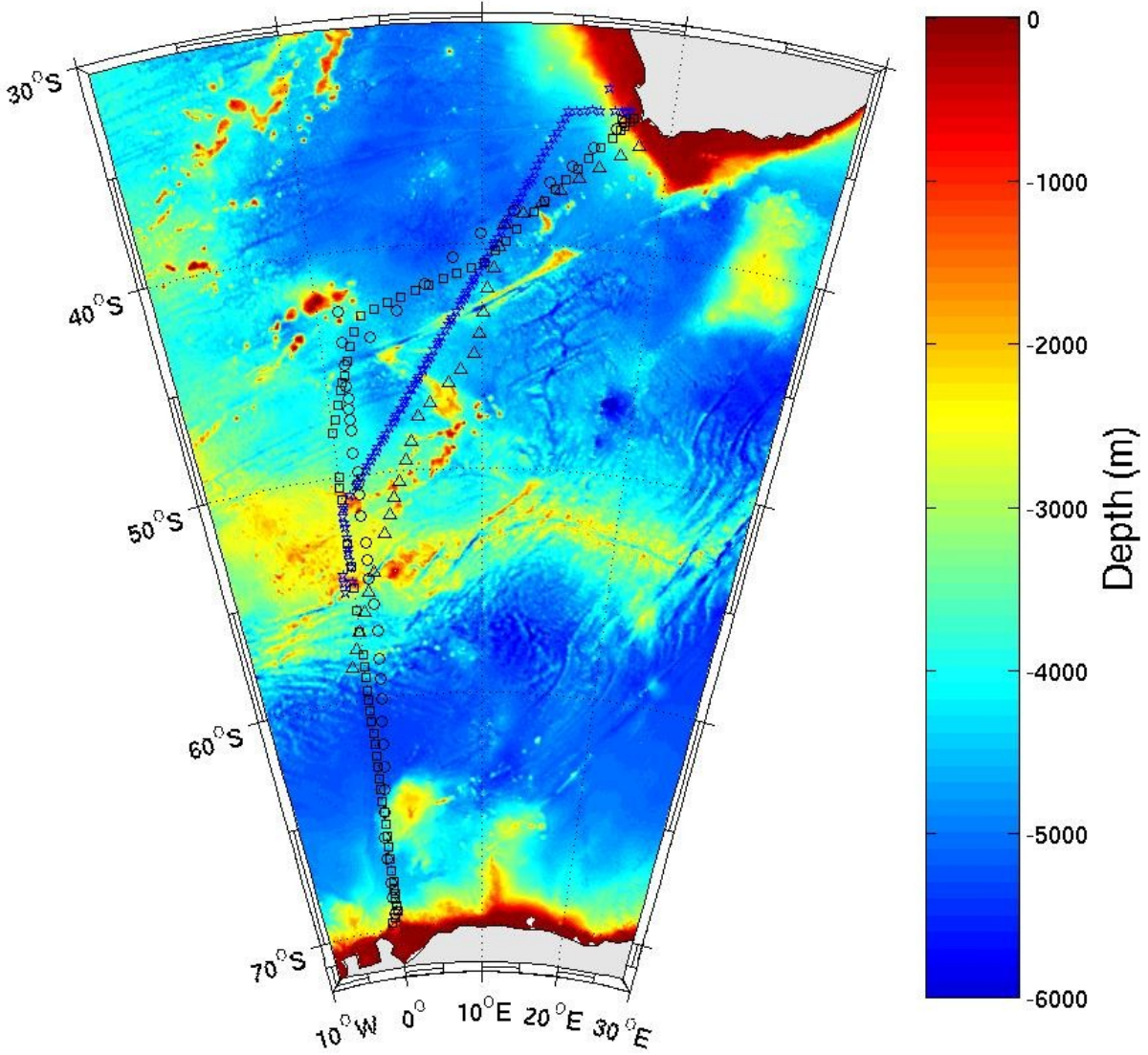

794Figure 2. Locations of the six CTD sections used in this study (Table 1). The AJAX section (circles), A21 795section (triangles), A12 section (squares), SR2 (diamonds), GoodHope 1 and 2 (stars). The section tracks 796have been overlaid on bathymetry (in meters). 
797

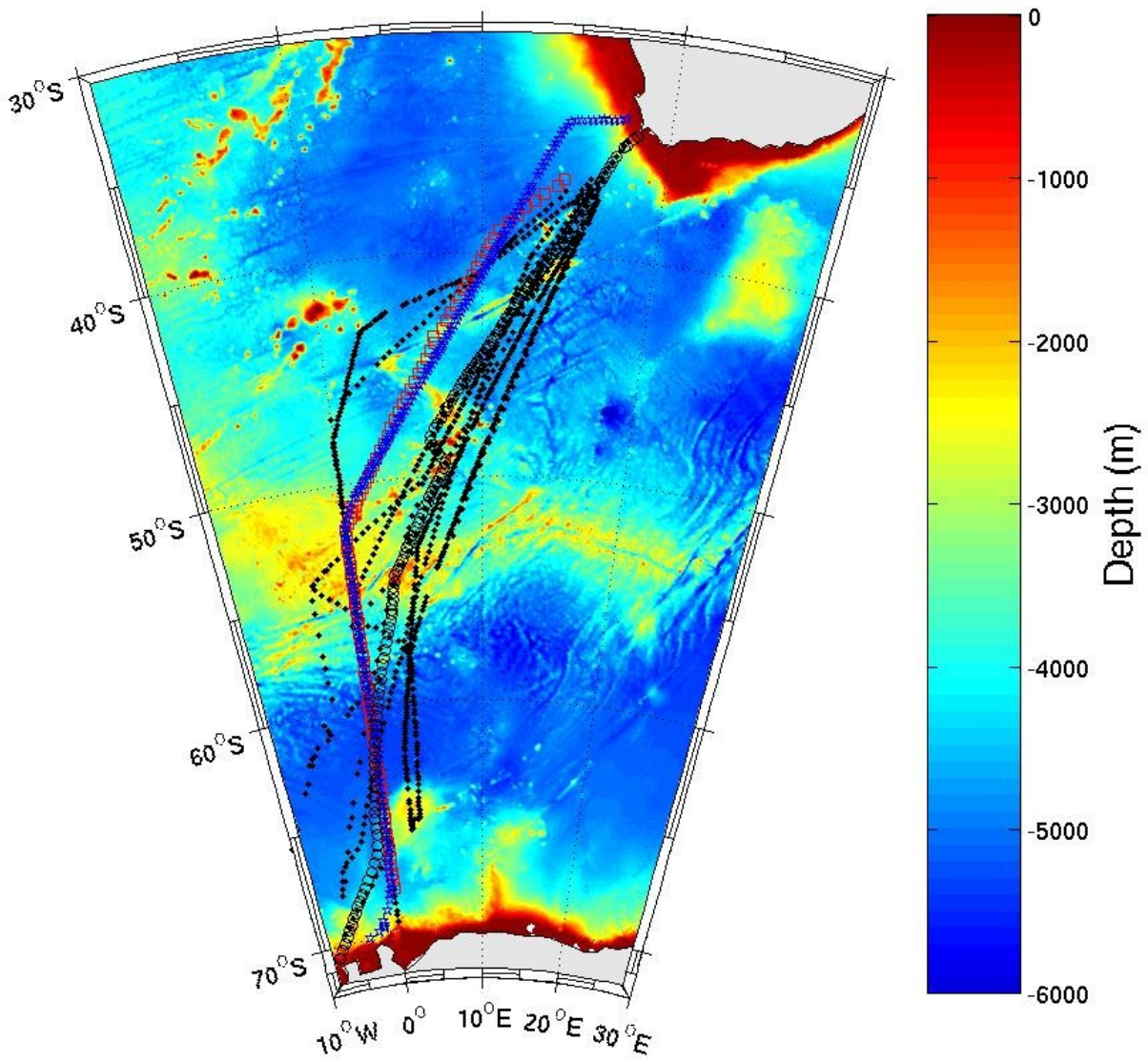

798Figure 3. Locations of the XBT stations used in this study. GoodHope repeat section (stars), AARI section 799(squares), AWI sections (dots) and the AA-CT section (circles). The section tracks have been overlaid on 800bathymetry (in meters). 

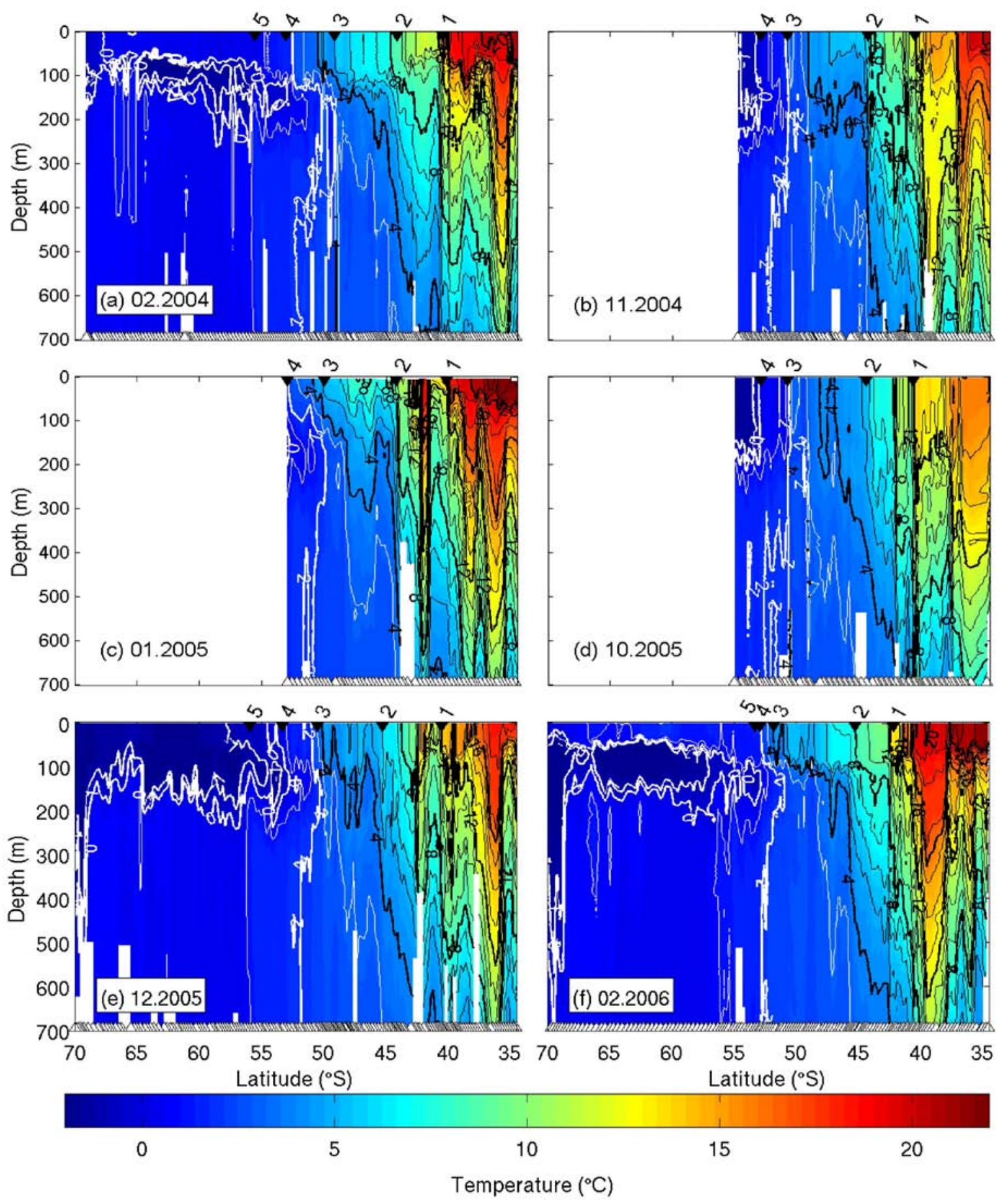

801Figure 4. Temperature sections for the following transects: (a) GoodHope 1: February 2004, (b) GoodHope 8022: November 2004, (c) GoodHope 3: January 2005, (d) GoodHope 4: October 2005, (e) GoodHope 5: 803December 2005, (f) Antarctica-Cape Town (AA-CT): February 2006. The black arrows show the latitudes 804 of the ACC fronts (from north to south: STF (1), SAF (2), APF (3), sACCf (4), SBdy (5)). Triangles, along 805 the bottom x-axis, indicate station positions. Note that the figures have equal axes of depth and latitude. 


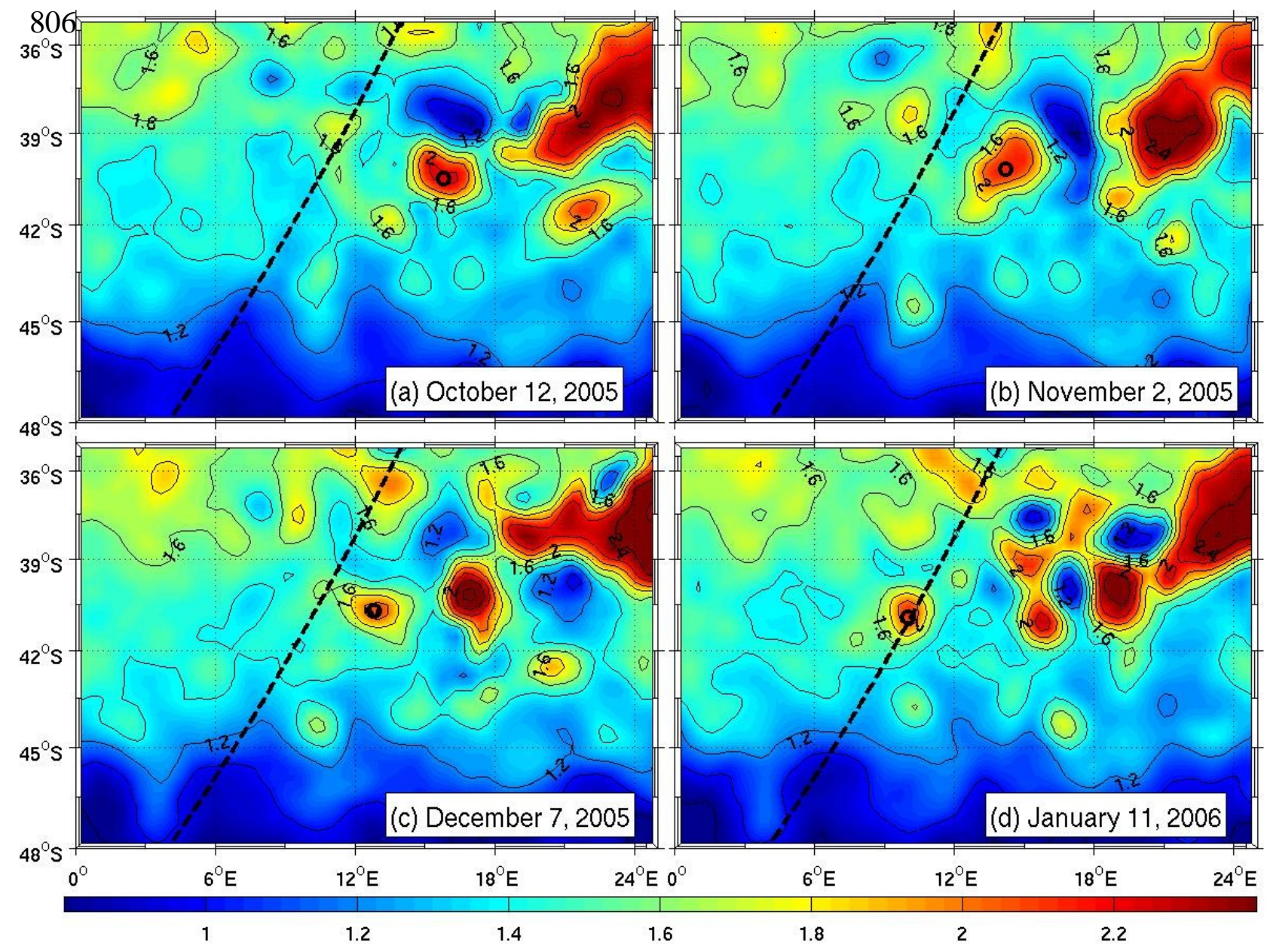

807Figure 5. The MADT data (in dyn $\mathrm{m}$ ) for the region located near the GoodHope cruise track between 808October 12, 2005 and January, 11, 2006. The propagation of an Agulhas Ring, marked with a black circle 809 near its core, crosses the GoodHope cruise track (dashed line), at approximately $40^{\circ} \mathrm{S}$. 

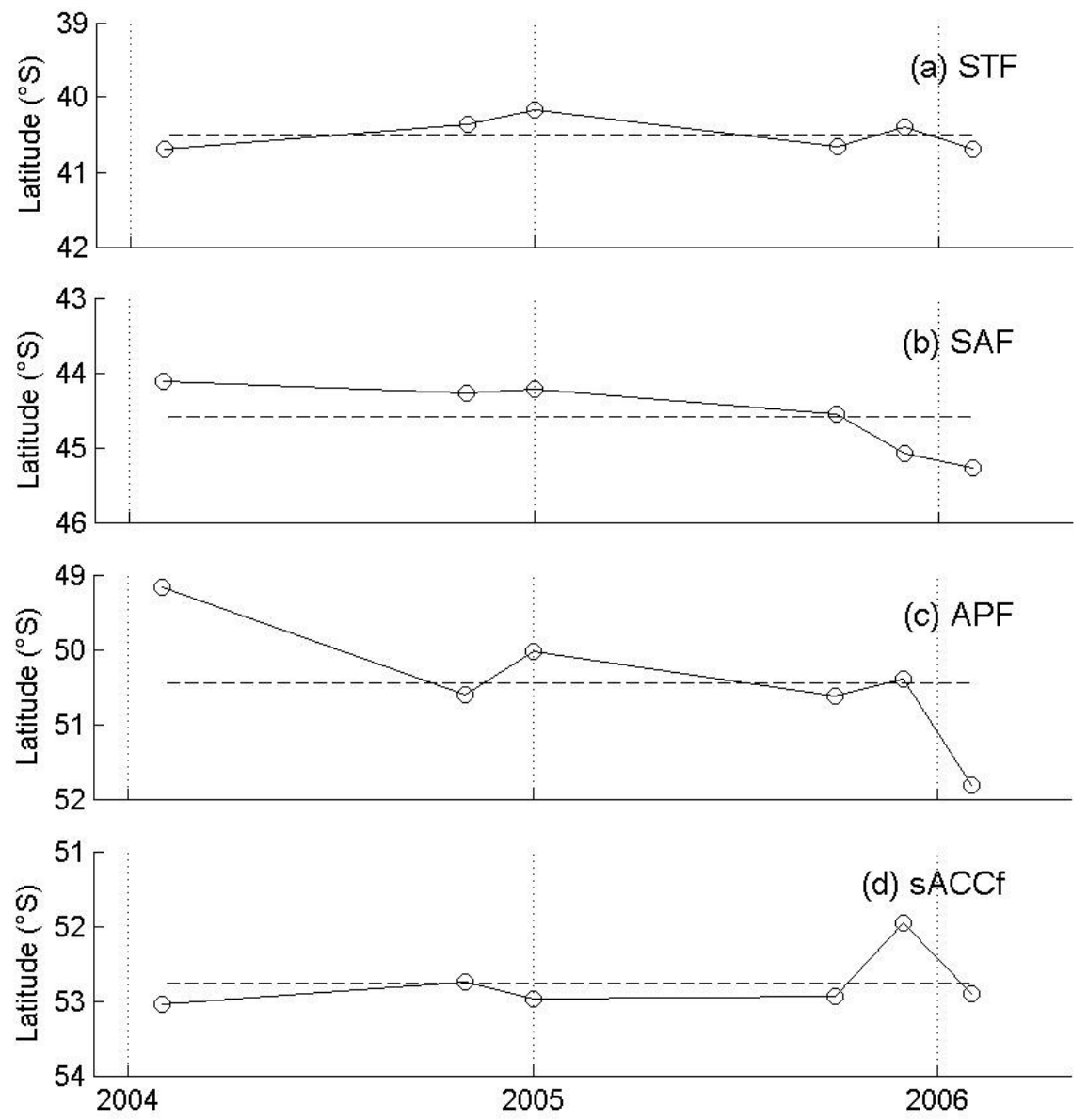

811Figure 6. Latitudes of the (a) STF, (b) SAF, (c) APF, (d) sACCf for the Africa to Antarctica transects 812 completed between 2004-2006. The dashed line depicts the mean frontal position for six transects. 
813

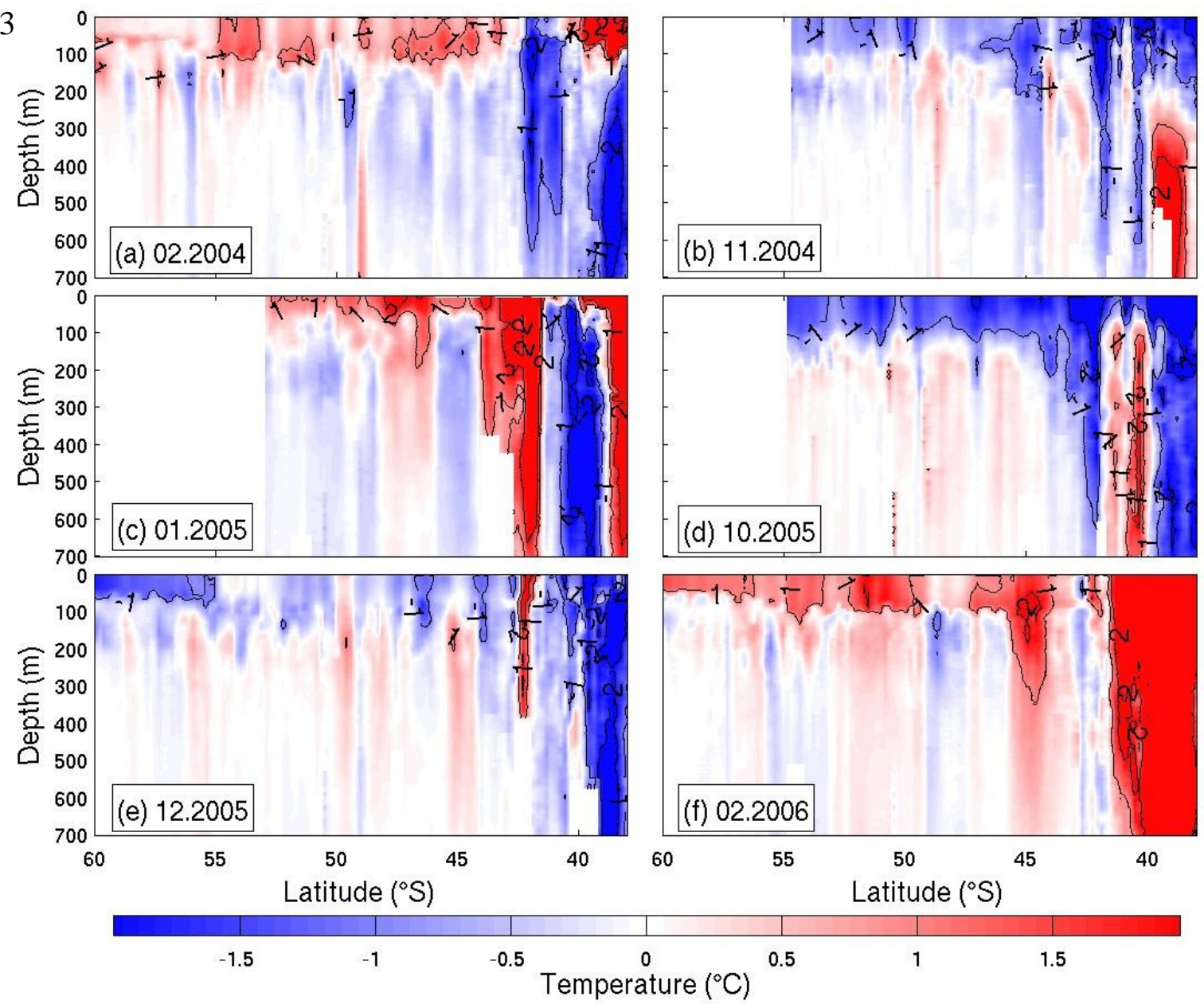

814Figure 7: Temperature anomaly sections for the following transects: (a) GoodHope 1: February 2004, (b)

815GoodHope 2: November 2004, (c) GoodHope 3: January 2005, (d) GoodHope 4: October 2005, (e) 816GoodHope 5: December 2005, (f) Antarctica-Cape Town (AA-CT): February 2006. 


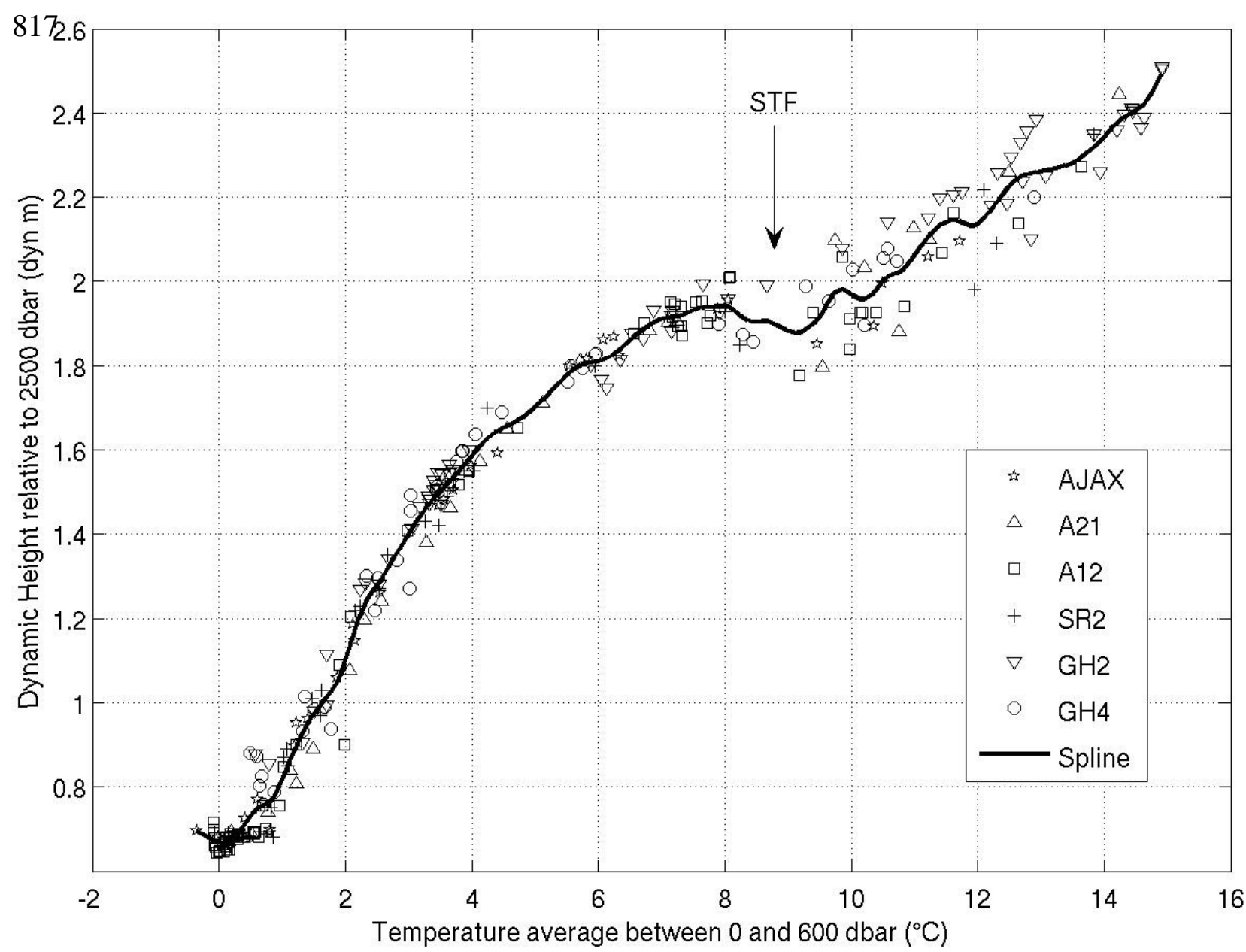

818Figure 8. Dynamic height at the surface, relative to $2500 \mathrm{dbar}$, versus temperature averaged between the 819surface and 600 dbar. Data comes from six CTD transects completed in the south Atlantic: AJAX (stars), 820A21 (triangles), A12 (squares), SR2 (crosses), GH2 (down triangles), GH4 (circles). The solid curve 821 depicts a smoothing spline fit to the data. 


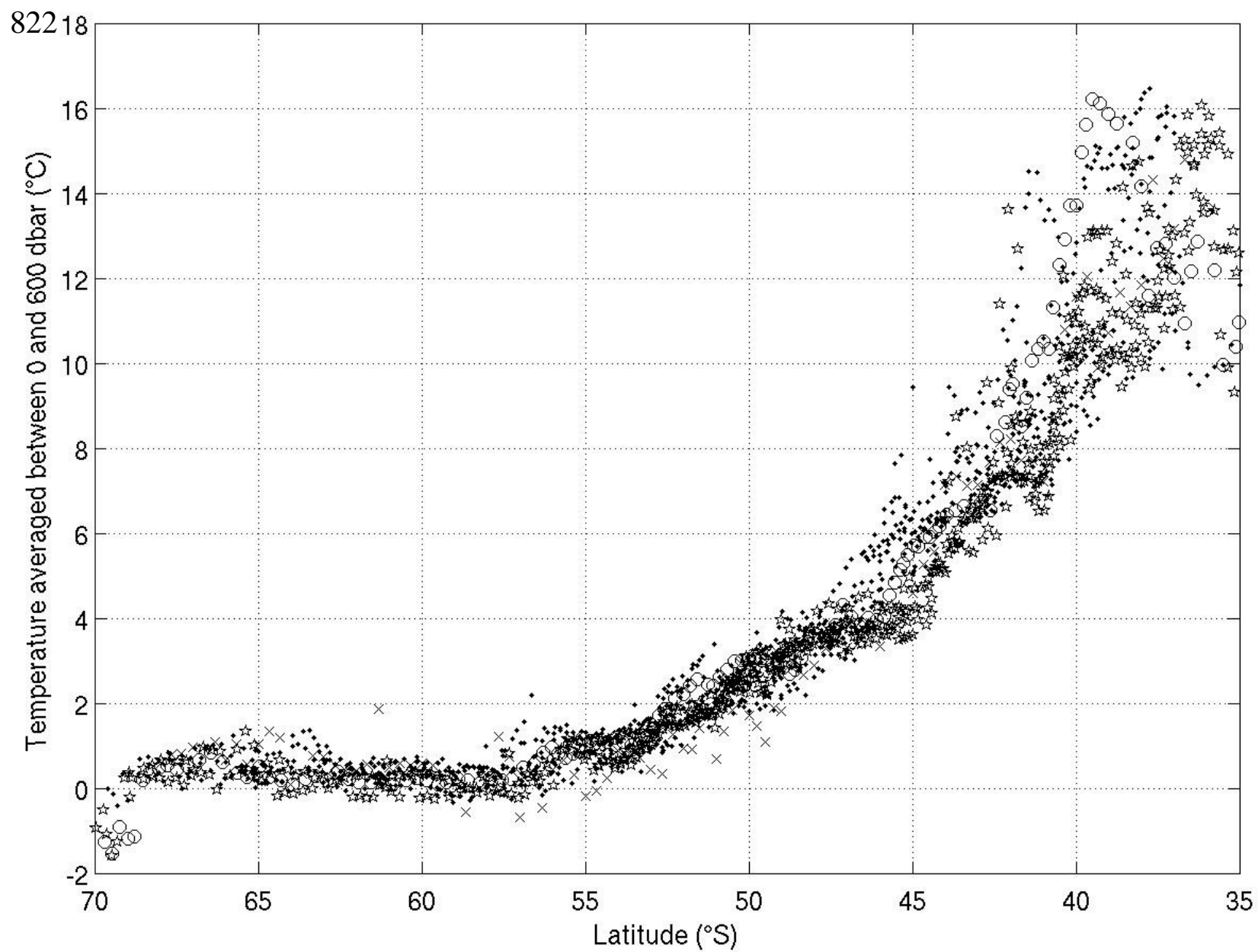

823Figure 9. Average temperature, between 0 and $600 \mathrm{dbar}$, versus latitude for 18 XBT sections, completed in 824the South-East Atlantic. Data comes from repeat GoodHope sections (stars), AA-CT section (circles), AWI 825 sections (dots) and an AARI section (crosses). 

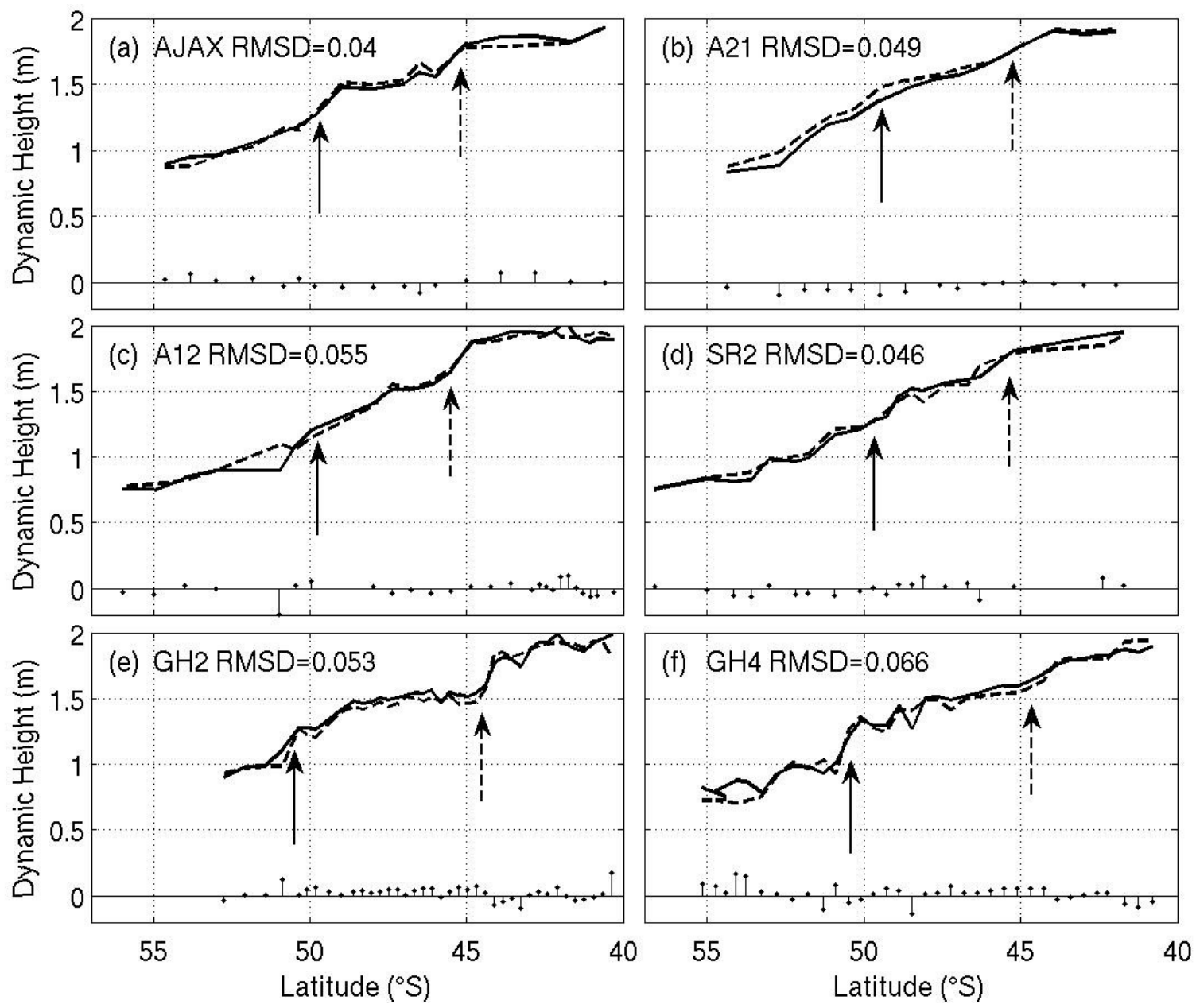

827Figure 10. Comparison of 'true' dynamic height, above $2500 \mathrm{dbar}$ (solid line), and dynamic height derived 828 from the empirical relationship (dashed line) between upper ocean temperature and dynamic height in 829Figure 8. The dashed and solid arrows represent the positions of the SAF and APF, respectively. 830Differences between the two dynamic heights are shown along the $x$-axis. The RMSDs are given in dyn m. 


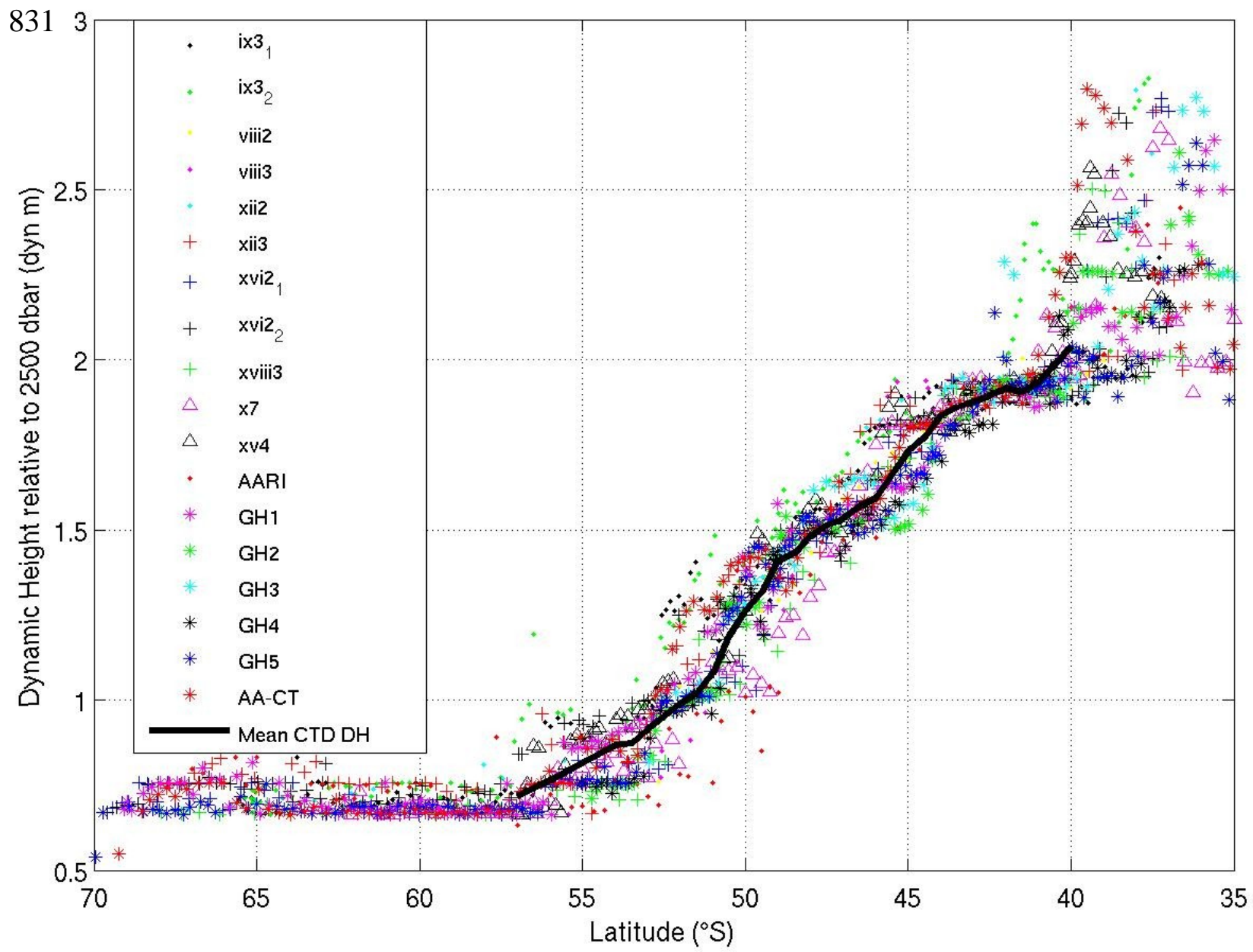

832Figure 11. Dynamic height at the surface, relative to $2500 \mathrm{dbar}$, calculated using the empirical relationship 833in Figure 8, versus latitude for 18 XBT sections. The solid line represents the mean dynamic height 834 calculated from temperature and salinity data from the six CTD transects. 


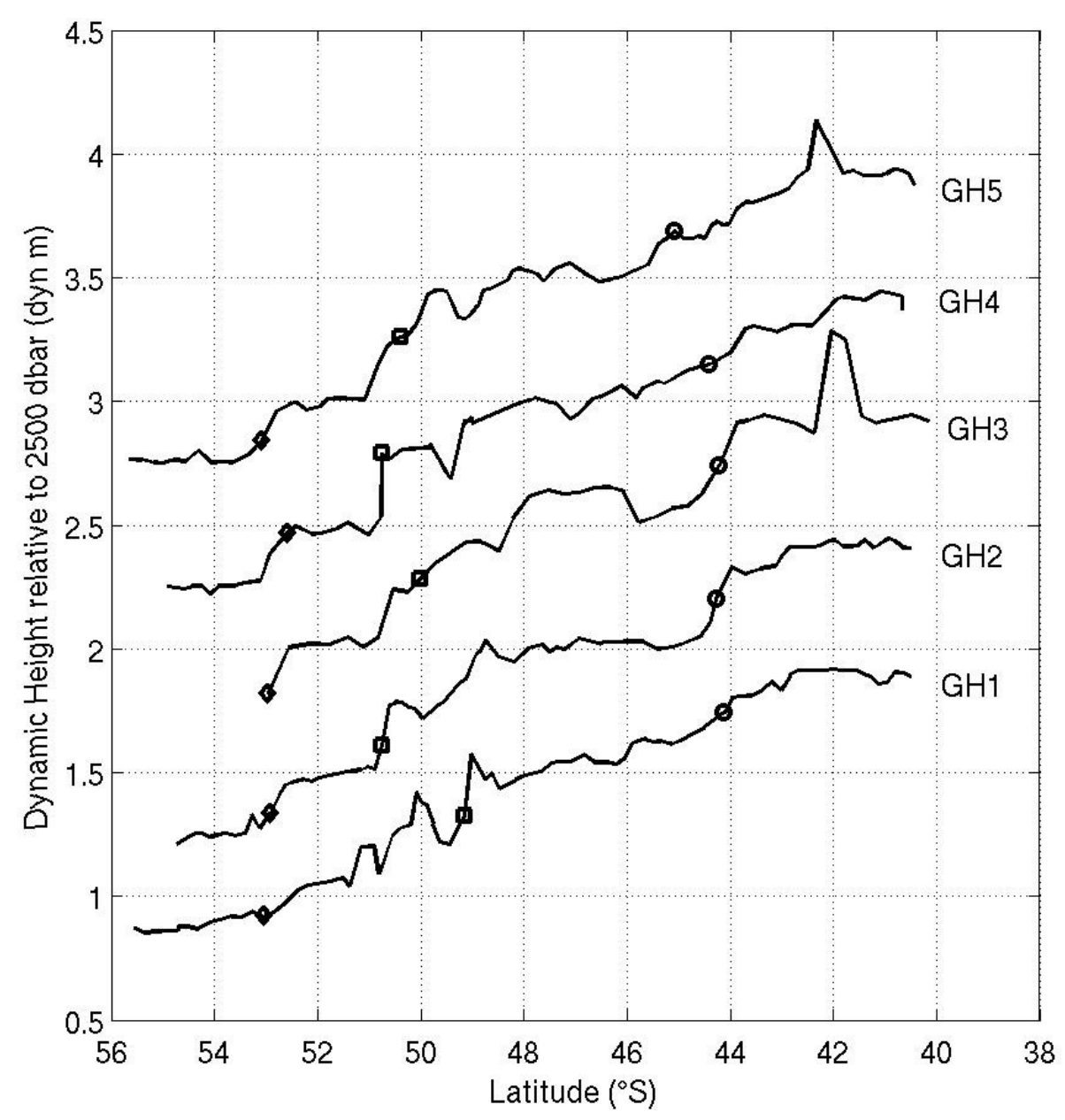

836Figure 12. Dynamic height at the surface, referenced to $2500 \mathrm{dbar}$, for five repeat GoodHope XBT sections 837(2004-2006), estimated using the regression relationship in Figure 8. The estimated dynamic heights 838 between sections are offset by $0.5 \mathrm{dyn} \mathrm{m}$ for clarity. The offset begins from the first section (GH1). The 839 markers along each profile represent the latitudes (found using the temperature sections) of the SAF 840(circles), APF (squares) and the sACCf (diamonds). 


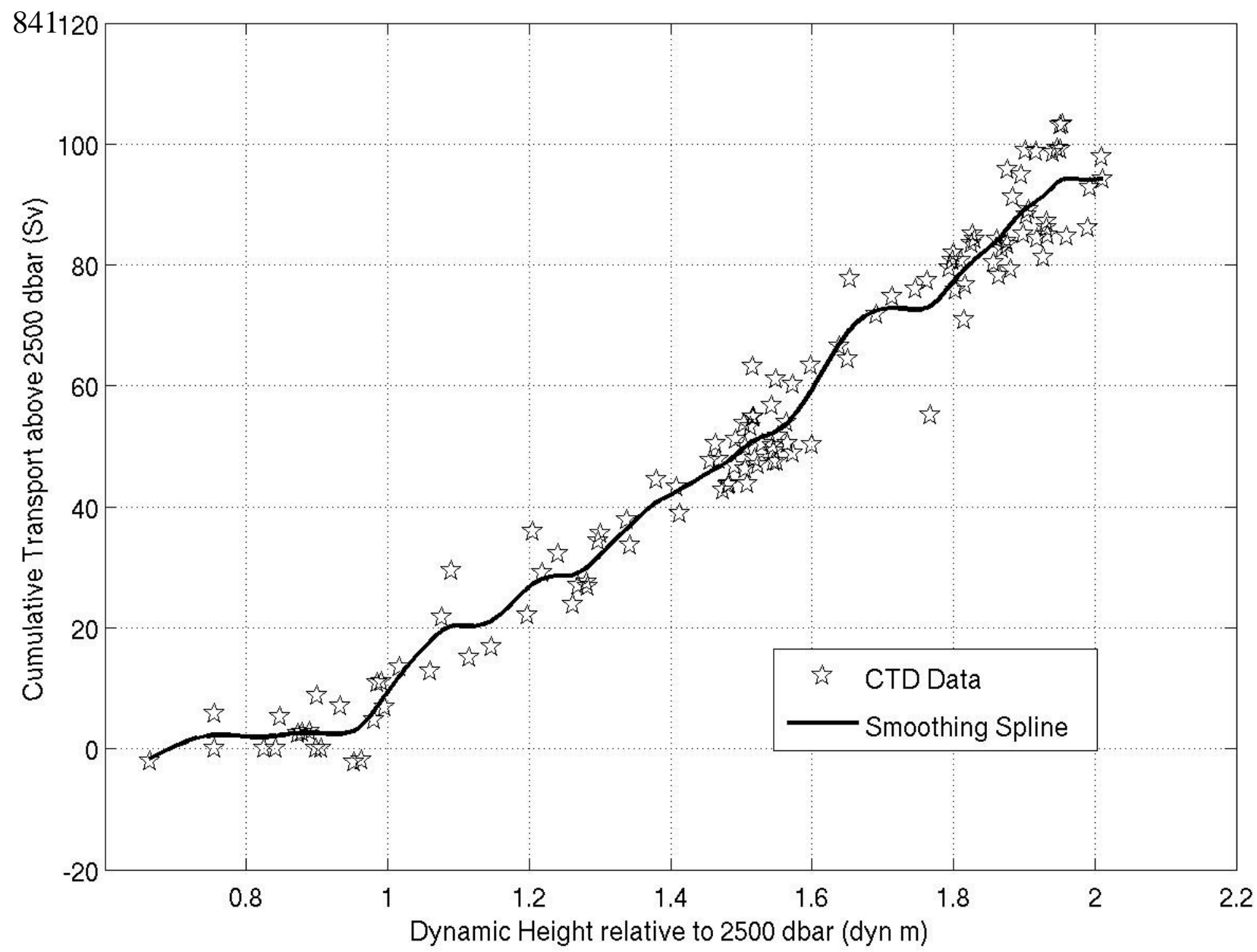

842Figure 13. Northward baroclinic cumulative transport (above and relative to 2500 dbar) versus dynamic 843height at the sea surface, relative to $2500 \mathrm{dbar}$, of five CTD transects completed in the South-East Atlantic 844(including two occupations of GoodHope). The solid curve depicts a smoothing spline fit to the data. 

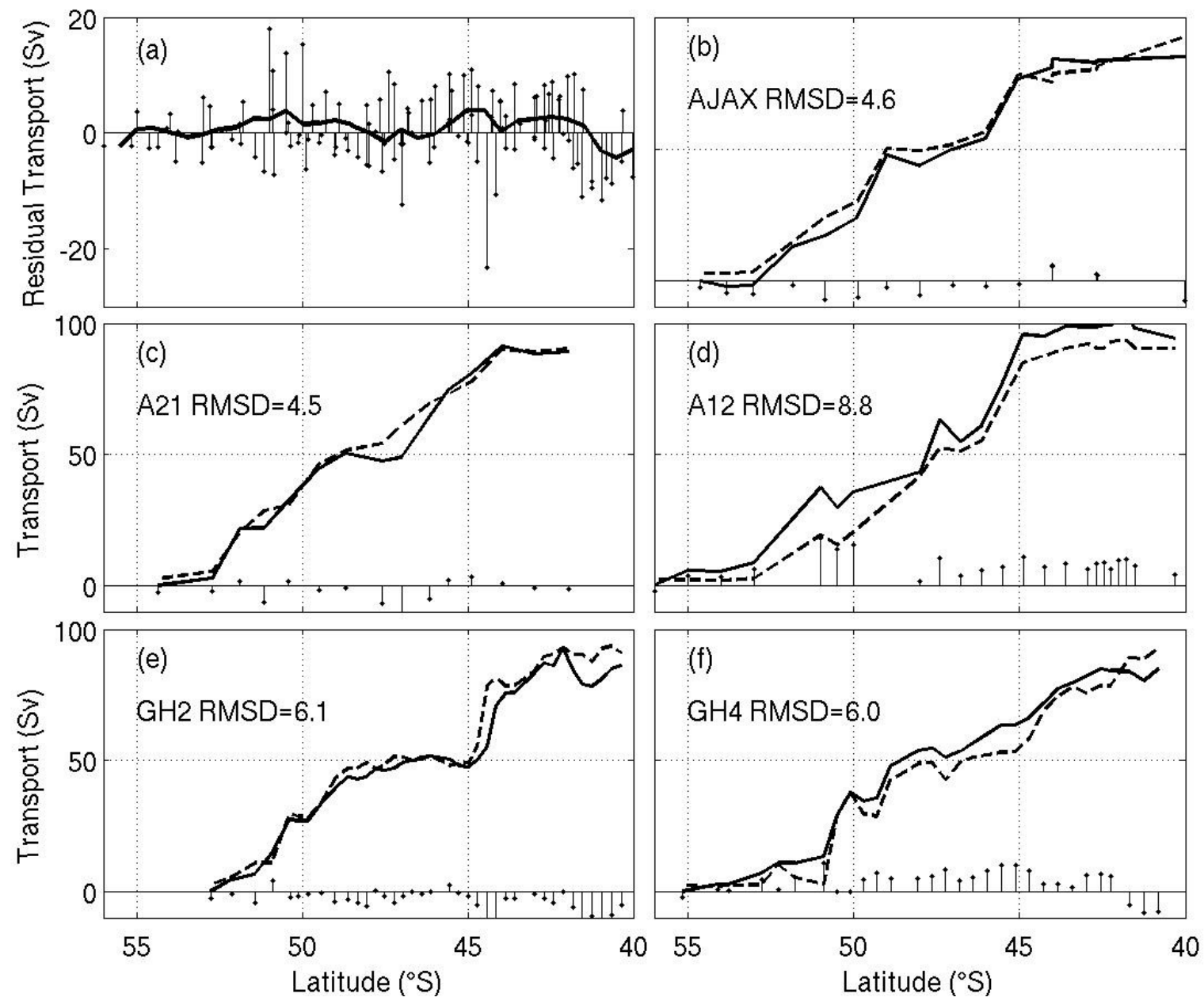

846Figure 14. Comparison of baroclinic transport, relative to $2500 \mathrm{dbar}$ (solid line), from CTD data, and 847 baroclinic transport, derived from the empirical relationship (dashed line) in Figure 13. The comparisons 848are made from five CTD sections. Differences between the two transports are shown along the x-axis. The 849RMSDs are given in Sv. The differences between the curves (in Sv) are shown along the $\mathrm{x}$-axis and are 850summarised in (a). The solid line, in (a), shows the mean residual plotted as a function of latitude. 
851
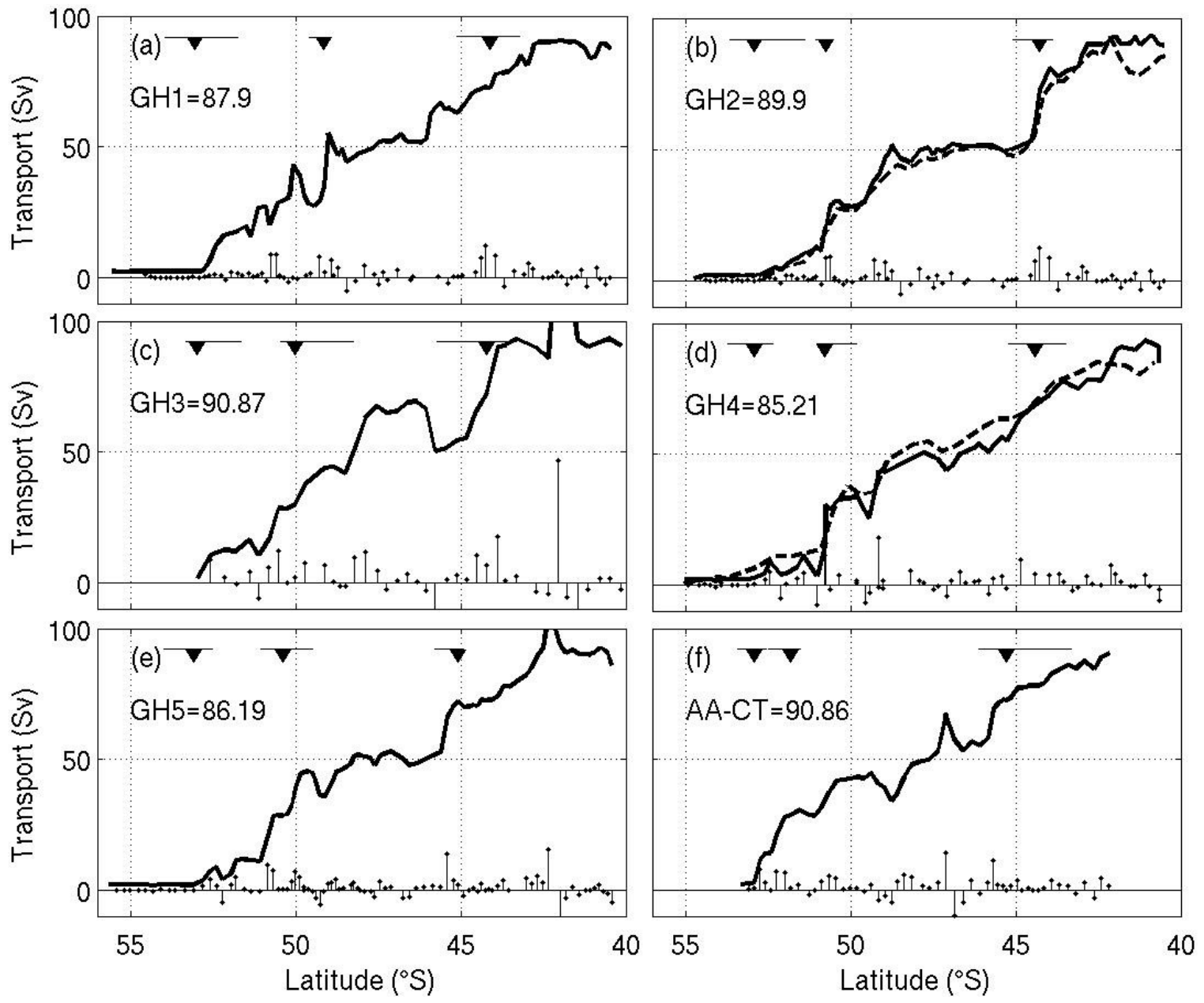

852Figure 15. Northward cumulative baroclinic transport (referenced to $2500 \mathrm{dbar}$ ) for five repeat GoodHope $853 \mathrm{XBT}$ transects and the AA-CT section (bold line). The equivalent geostrophic transports from the CTD 854sections are shown for GoodHope 2 and 4 (dashed line). Differences in transport at each station pair are 855 shown along the x-axis. The net cumulative baroclinic transport (in Sv) is given next to each section label. 856The positions of the three inner ACC fronts, determined from the temperature sections, are represented by 857the arrows (from south to north: sACCf, APF, SAF). The transport integration limits for each of these 858 fronts is represented by the bar, placed above each arrow. 


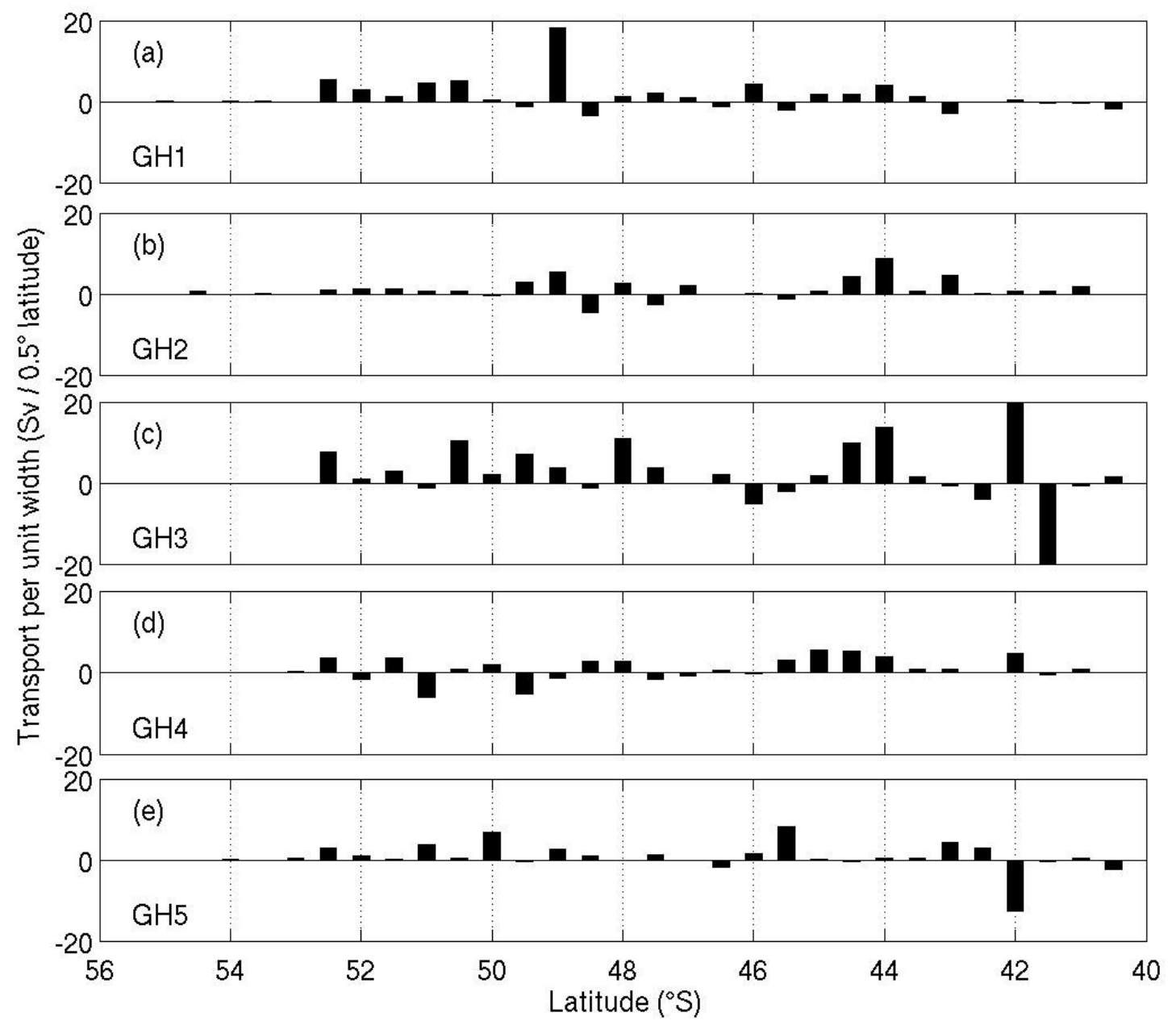

860Figure 16. Baroclinic transport across the GoodHope sections per half degree latitude for five repeat 861 occupations of GoodHope. Eastward flow is positive. 

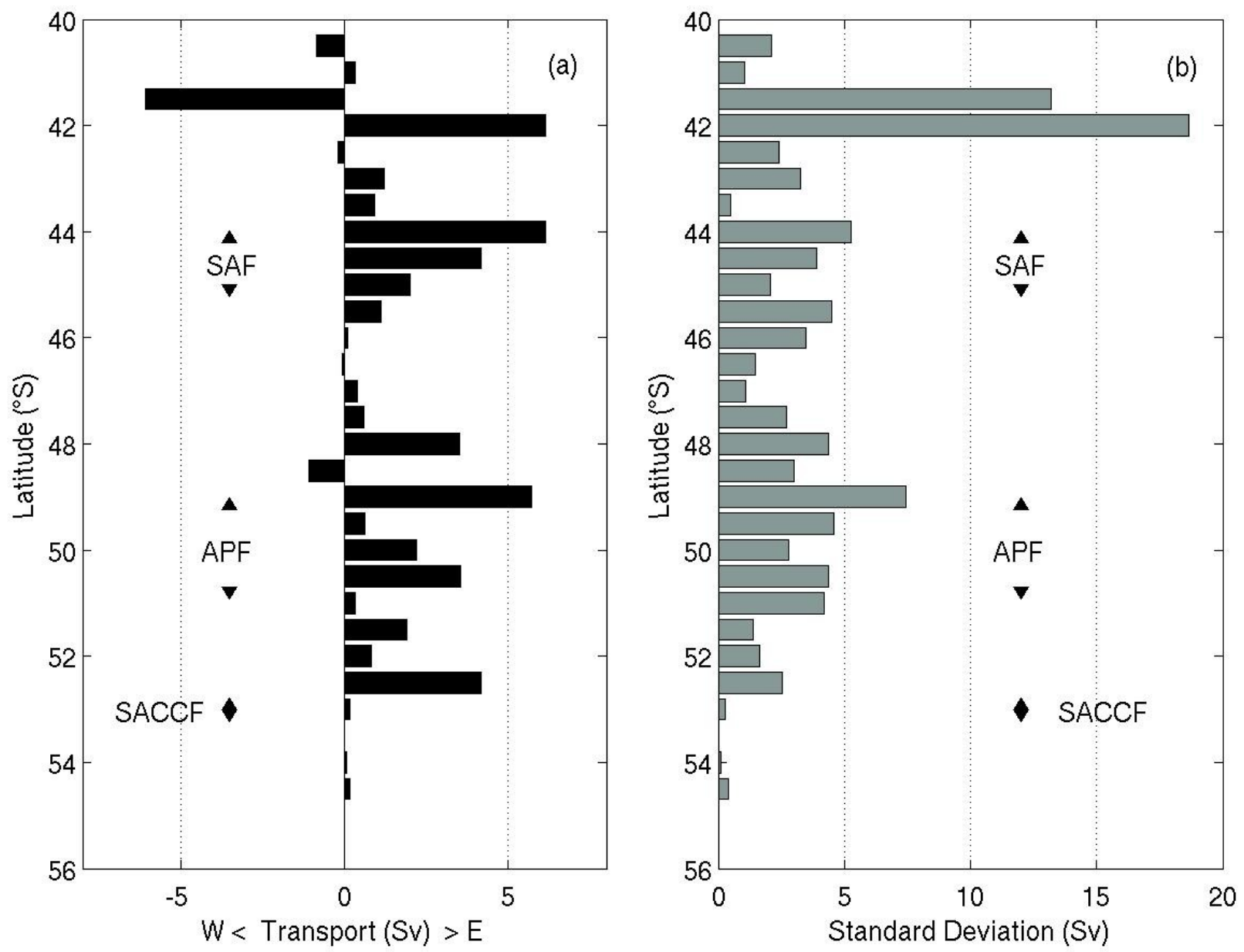

863Figure 17. (a) Mean baroclinic transport, relative to $2500 \mathrm{dbar}$, per half degree latitude for five occupations 864of GoodHope. Eastward flow is positive. (b) The standard deviation of cumulative baroclinic transport for 865the half degree latitude bands is given. The arrows indicate the latitudinal range of the three inner ACC 866hydrographic fronts (SAF, APF sACCf), during five repeat GoodHope occupations. 

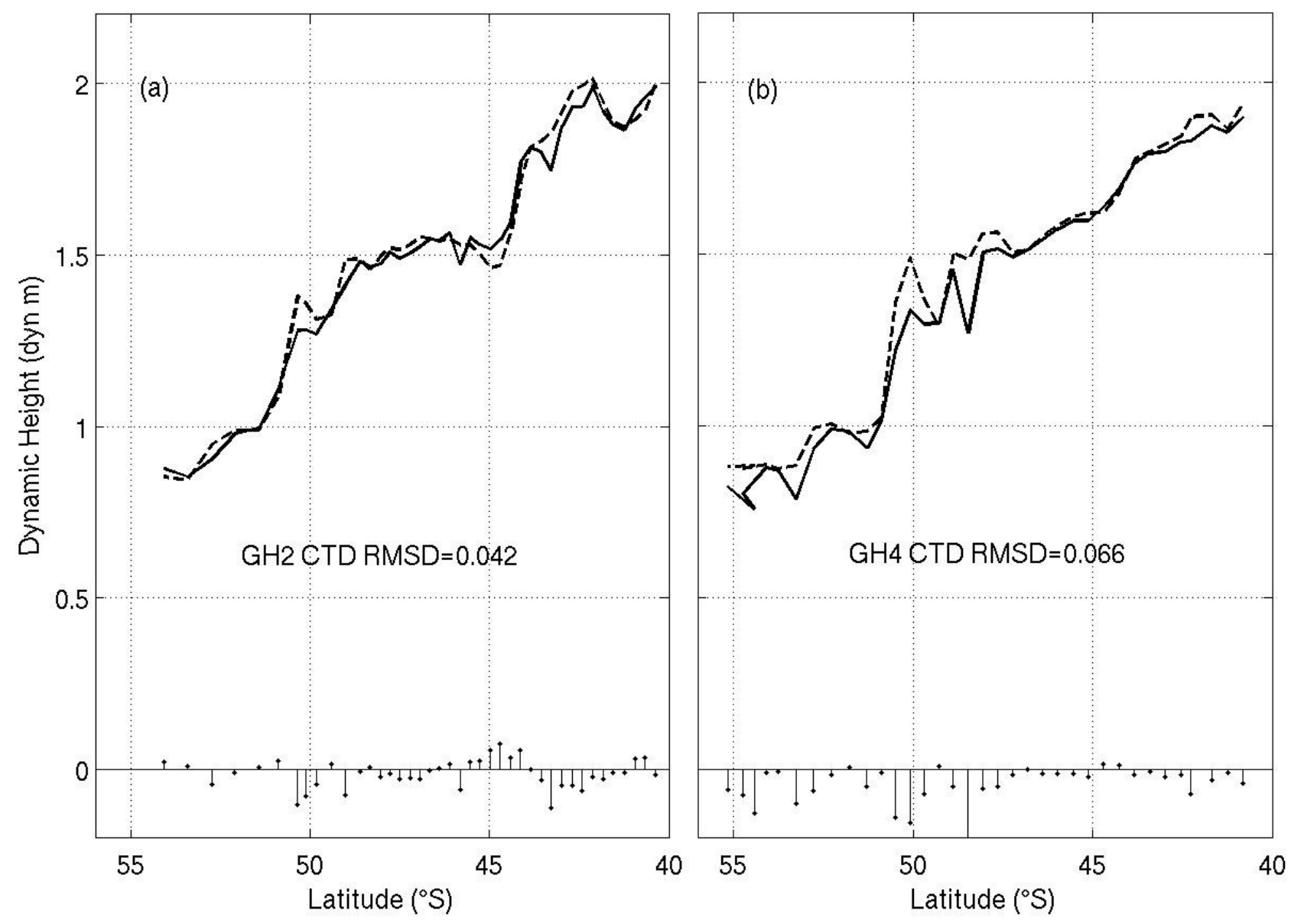

865Figure 18. Comparison of surface dynamic height, relative to $2500 \mathrm{dbar}$, from CTD data (solid line) and 866from the ADT produced using altimetry data (dashed line), for two occupations of the GoodHope cruise 867 track. The differences between the two estimates are shown along the x-axis. 

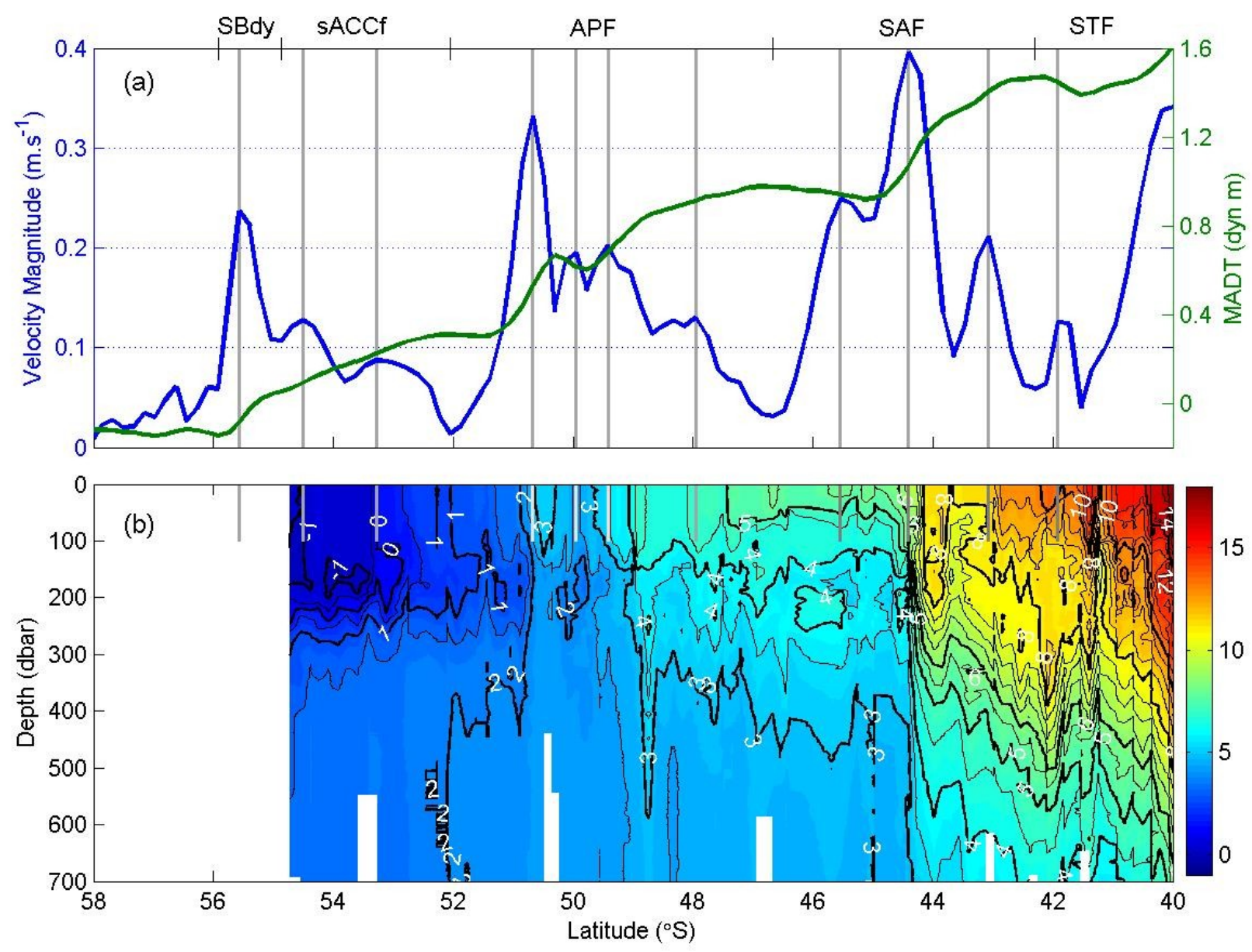

867Figure 19. (a) Surface velocity magnitudes (solid blue line) and MADT data (solid green line) identify the 868transport jets (marked with vertical solid grey lines), associated with the ACC fronts. The proposed limits 869 of each front, associated with this example, are indicated on the upper x-axis. (b) High resolution 870 temperature data (combination of CTD and XBT temperature profiles; in ${ }^{\circ} \mathrm{C}$ ) obtained during the second 871 GoodHope crossing are used to show the vertical thermal structure associated with the transport jets 872 identified in the upper figure panel. 


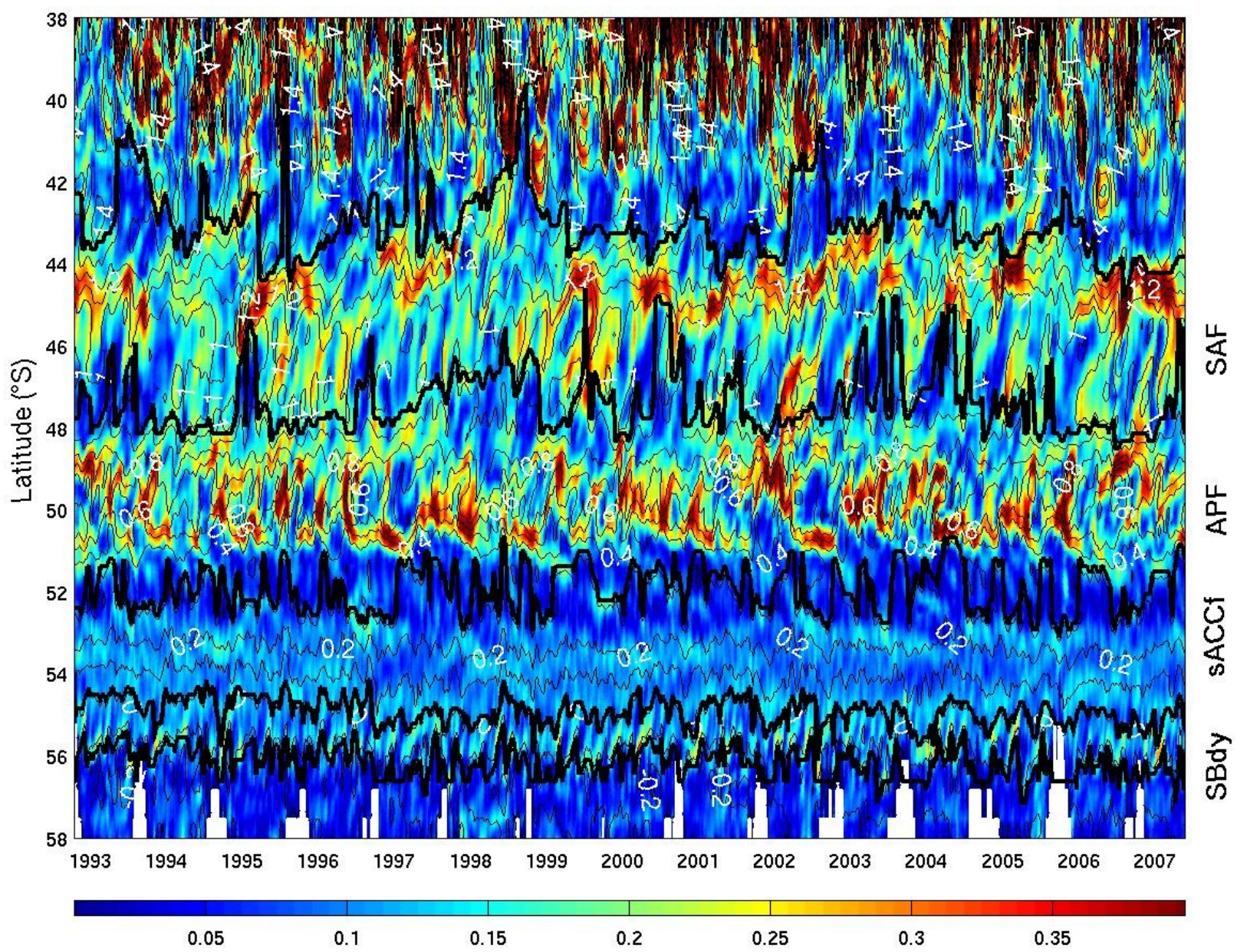

869Figure 20. Time series of velocity magnitudes (colour surface plot; in $\mathrm{ms}^{-1}$ ) and MADT (thin black lines; in 870dyn m) over the GoodHope cruise track. The boundaries between each ACC front (excluding the northern $871 \mathrm{STF})$ are illustrated using the thick black lines. 

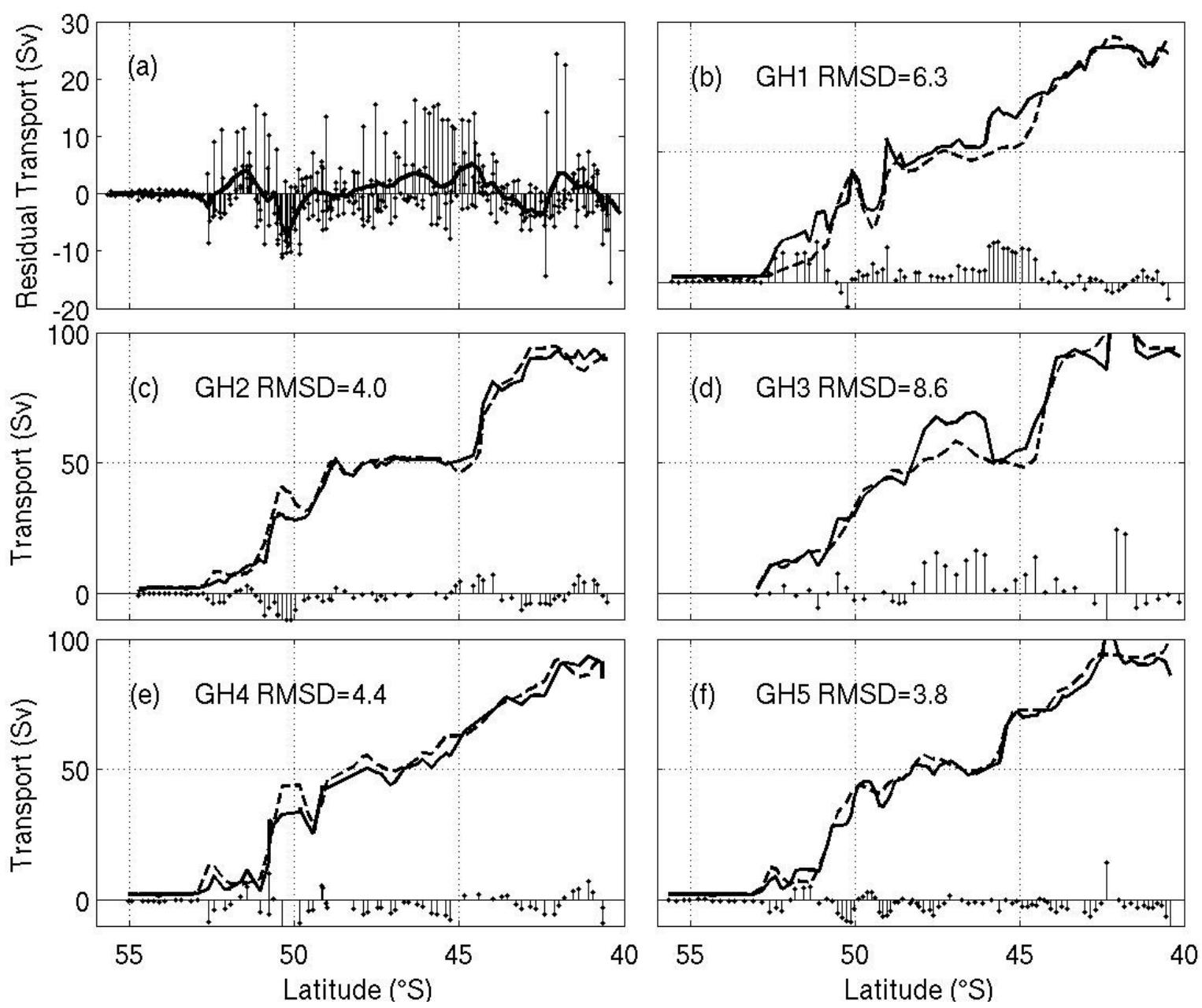

871Figure 21. Comparison between baroclinic transport estimated from the ADT (dashed line) and from XBT 872 dynamic height data (solid line; $b$ through $\mathrm{f}$ ), for five occupations of the GoodHope track. The differences 873 between two transport estimates (in Sv) are shown along the x-axis and summarised in (a); the solid line is 874the mean residual plotted against latitude. 


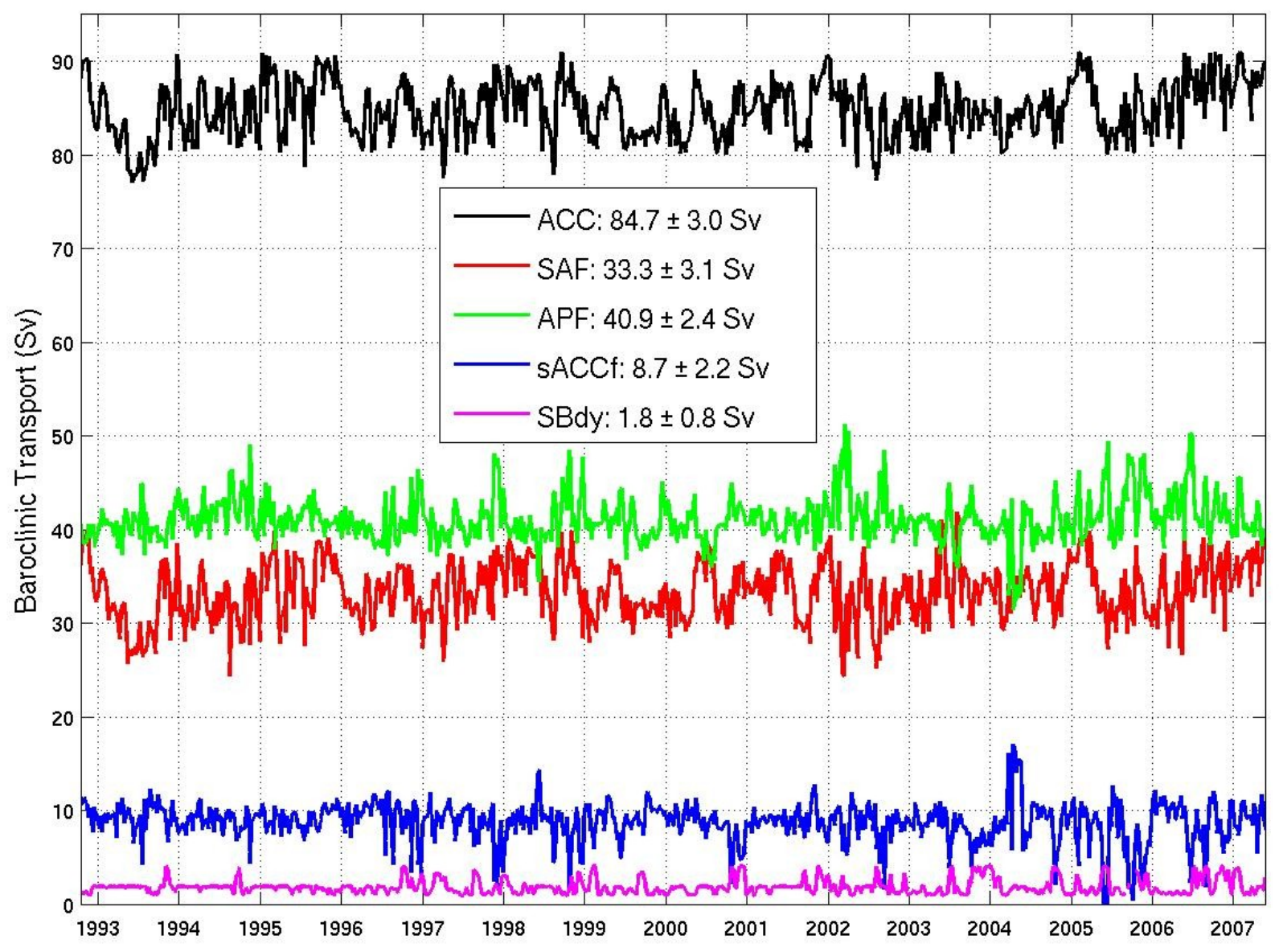

873Figure 22. Time series of baroclinic transport, relative to $2500 \mathrm{dbar}$, for each ACC front and for the whole 874ACC domain (cumulated from the southern limit of the SBdy to the northern limit of the SAF), between 8751992-2007. The legend depicts the mean transport and standard deviation of the transport time series for 876 each respective domain. 

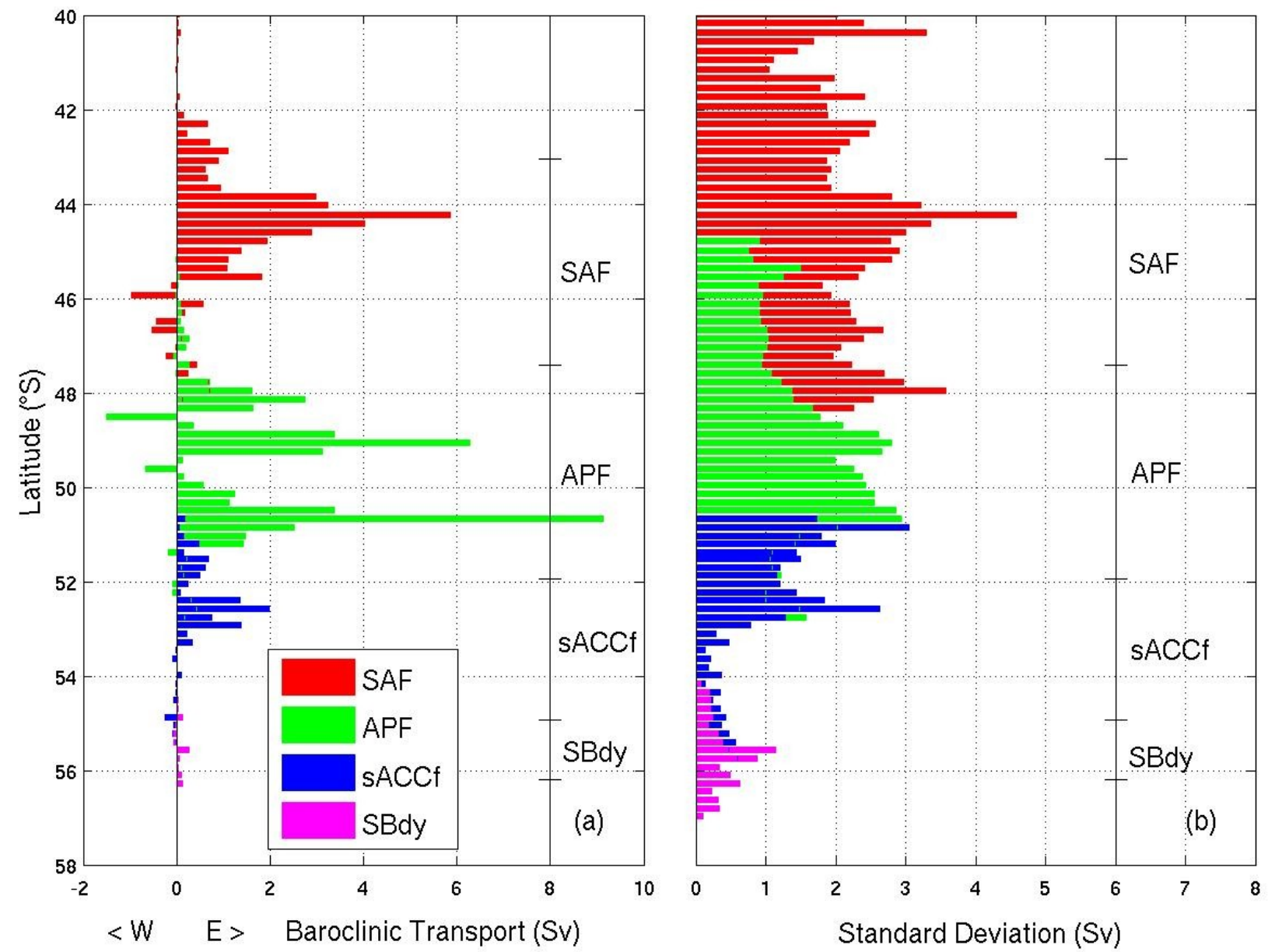

875Figure 23. (a) Mean baroclinic transport per ACC front derived using the ADT data (between 1992-2007), 876plotted as a function of latitude. Eastward flow is positive. (b) The standard deviation of the baroclinic 877 transport, plotted as a function of latitude. The mean frontal limits, as defined in Figure 20, are indicated on 878each plot. 